\title{
DERECHOS HUMANOS Y EXPORTACIÓN LEGAL DE ARMAS: ESTADOS UNIDOS Y ALEMANIA FRENTE A LA CRISIS MEXICANA
}

\author{
HUMAN RIGHTS AND LEGAL ARMS EXPORTS: \\ THE UNITED STATES AND GERMANY IN LIGHT \\ OF THE CRISIS IN MEXICO
}

\section{LES DROITS DE L'HOMME ET L'EXPORTATION LÉGALE D'ARMES: LES ÉTATS-UNIS ET L'ALLEMAGNE FACE À LA CRISE MEXICAINE}

\author{
Carlos A. Pérez Ricart \\ Universidad de Oxford \\ cperezricart@gmail.com \\ JoHn Lindsay-Poland \\ Global Exchange \\ Johnlindsaypoland@gmail.com
}

Resumen: Se examina la forma en que Alemania y Estados Unidos han adaptado sus leyes y políticas de control de exportación de armas cortas y ligeras (sALw, por sus siglas en inglés) frente a México, país que pasa actualmente por una severa crisis de derechos humanos. A partir de entrevistas efectuadas en Alemania y Estados Unidos, así como de reportes oficiales y bibliografía secundaria, el artículo identifica que mientras Alemania ha retraído sus exportaciones de SALw a México, las empresas estadounidenses continúan exportando prácticamente sin restricciones. El texto presenta contribuciones a dos debates académicos: el estudio de la participación de actores no estatales en el proceso de toma de decisiones en política de exportación de armas y el examen de cómo las normas internacionales afectan el comportamiento y las prácticas de los Estados nacionales, un tema clave en la agenda constructivista de las relaciones internacionales.

Palabras clave: control de armas; derechos humanos; armas pequeñas y ligeras (SALW); seguridad; normas internacionales. 
Aвstract: This paper examines how Germany and the United States have altered their laws and policies for the control of Small Arms and Light Weapons (SALW) exports to Mexico, a country currently experiencing a severe human rights crisis. Based on interviews carried out in Germany and the United States, and official reports and secondary materials, the paper identifies that while Germany has withdrawn salw exports to Mexico, us companies continue to export them with practically no restrictions. The text offers contributions to two academic debates: the study of the participation of non-state actors in the decision-making process on arms export policies, and the examination of how international norms affect the behavior and practices of nation states, a key issue in the constructivist agenda of international relations.

Keywords: arms control; human rights; Small Arms and Light Weapons

(SALW); security; international norms.

\section{Traducción de Gonzalo Celorio Morayta}

RÉsumÉ: L'article analyse dans quelle mesure l'Allemagne et les États-Unis ont adapté, ou non, leurs lois et leurs politiques pour contrôler les ventes d'armes légères et de petit calibre -SALW en anglais-au Mexique, où se déroule de nos jours une grande crise des droits de l'homme. Des entretiens menés en Allemagne et aux États-Unis, ainsi que l'examen de rapports officiels et de la bibliographie sur le sujet, permettent d'établir que l'Allemagne a limité ses ventes de SALW au Mexique, tandis que les producteurs américains continuent de les exporter pratiquement sans restriction. Nous espérons contribuer à deux débats intellectuels, dont l'un concerne la participation d'acteurs non gouvernementaux à la prise de décisions se rapportant aux politiques sur la vente d'armes, et l'autre questionne l'effet des normes internationales sur le comportement et les pratiques des États, un sujet clef de l'agenda constructiviste des relations internationales.

Mots clefs: contrôle des armes, droits de l'homme, armes légères et de petit calibre (SALW), sécurité, normes internationales.

\section{Traducción de Bernardo Mabire}

Fecha de recepción: junio de 2018

Fecha de aceptación: noviembre de 2018 
A pesar de que los conflictos contemporáneos tienen como rasgo distintivo una manifiesta dimensión étnica y doméstica, el mercado de armas cortas y ligeras (las llamadas SALW, acrónimo de small arms and light weapons $)^{1}$ tiene un fuerte componente internacional; las armas y municiones que catalizan las guerras modernas provienen de más de mil empresas de unos sesenta países que las exportan y fabrican alrededor del mundo. ${ }^{2}$

$\mathrm{Al}$ menos en su primer ciclo de vida, prácticamente todas las SALW son producidas e intercambiadas en condiciones legales y a través de cuatro modalidades: en el marco de amplios programas de cooperación -habitual en la Unión Europea y entre los países de la Organización de Estados del Atlántico Norte (OTAN)-, en el marco de acuerdos de seguridad bilaterales, en convenios entre dos empresas particulares y, lo más común, a partir de contratos entre empresas particulares y burocracias estatales; en esta última modalidad, los Estados tienen la facultad de expedir permisos de exportación de acuerdo con una serie de criterios preestablecidos.

${ }^{1}$ La definición de sAlw es casi siempre problemática y difiere según el gobierno, instituto de investigación u organización no gubernamental que trabaje el tema. Por su funcionalidad, en este artículo se las definirá como sistemas o unidades que disparan proyectiles y que pueden ser cargadas y transportadas por un individuo, un pequeño número de personas, un animal o vehículo ligero. Armas pequeñas son, entre otras, pistolas, revólveres, rifles, rifles de asalto y ametralladoras ligeras -normalmente bípedas y con calibres medianos o bajos-. En la categoría de armas ligeras entran, en cambio, ametralladoras más pesadas -casi siempre trípodes- lanzagranadas, fusiles sin retroceso, lanzacohetes, morteros de hasta 120 milímetros, sistemas de misiles antiaéreos (portátiles), granadas, minas y explosivos. Véase: Small Arms Survey, "Documenting Small Arms and Light Weapons" (nota informativa), Ginebra, Small Arms Survey, 2015.

${ }^{2}$ Small Arms Survey, "Producers of Small Arms, Light Weapons, and their Ammunition”, Research Notes Weapons and Markets, 43, 2014. Véase también: S. Grillot, "Global Gun Control: Examining the Consequences of Competing International Norms”, Global Governance 17, núm. 4, 2011, pp. 529-555. 
El mercado de SALw es apenas una fracción del total del mercado de productos y servicios militares, cuya magnitud es del orden de casi 72000 millones de dólares anuales (2014). ${ }^{3}$ Aunque la cifra varía según el tipo de medición y definición utilizada, se estima que el intercambio legal de SALW, sus municiones, partes y accesorios ronda los $8500 \mathrm{mi}-$ llones de dólares anuales. ${ }^{4}$ En 2007, la Oficina de Naciones Unidas contra la Droga y el Delito (UNODC) calculó en 750 millones el número de sALw en el mundo; de ese total, aproximadamente $74 \%$ estaría en manos de civiles, $23 \%$ en posesión de militares y sólo $3 \%$ en posesión de cuerpos policiacos. Esto es, tres de cada cuatro armas cortas o ligeras estarían fuera del control estatal. ${ }^{5}$ Un gran porcentaje de este total corresponde a armas exportadas a países con importantes déficits en materia de derechos humanos, a regiones en conflicto o a zonas con un alcance limitado del Estado. Ante el problema que supone que armas vendidas de manera legal coadyuven a prolongar conflictos preexistentes o que terminen por ser revendidas en el mercado negro por burocracias estatales, desde hace más de un siglo se ha impulsado la construcción de marcos internacionales que regulen su exportación. ${ }^{6}$ Lo cierto es que éste sigue siendo un objetivo sin cumplir.

Dada la ausencia de un régimen vinculante, cada Estado ha establecido sus propias formas de control de armas. Esto es, mecanismos que regulan los límites de sus exportaciones de SALW. Naturalmente, éstos no son idénticos y responden a muchas variables, entre otras, la presión de grupos no estata-

3 C. A. Theohary, "Conventional Arms Transfers to Developing Nations, 2007-2014", Congressional Research Service, 2015, p. 3.

${ }^{4}$ Small Arms Survey, Small Arms Survey 2012: Moving Targets, Cambridge, University Press, 2012, p. 241.

${ }^{5}$ UNODC, Study on Firearms 2015, Viena, UNODC, 2015, p. 1.

${ }^{6}$ D. R. Stone, "Imperialism and Sovereignty: The League of Nations' Drive to Control the Global Arms Trade", Journal of Contemporary History 35, núm. 2, 2000, pp. 213-230. 
les, la inserción del tema en el marco global de la política exterior, la tradición, el peso del empleo en el sector, etcétera.

\section{Preguntas, OBJeto y Diseño De LA InVESTigación}

En este artículo nos preguntamos por la forma en que dos potencias exportadoras de SALW -Alemania y Estados Unidos- han implementado sus controles de exportación de armas en situaciones críticas. Desde un marco comparado, nos enfocamos en analizar la forma en que ambos países han adaptado su sistema de control de armas para el caso de México, país en el que entre 2006 y 2017 fueron asesinadas intencionalmente 150000 personas y desaparecidas varias docenas de miles más. Además, se han probado casos de colusión entre autoridades estatales y crimen organizado, uso indiscriminado y extrajudicial de la fuerza del Estado, así como "ataques generalizados y sistemáticos contra la población civil”. ${ }^{7}$ Relevante también para los fines de este texto es la evidencia de la falta de un registro confiable de armas, y los casos de miles de armas robadas y extraviadas en el país, lo cual sugiere la incapacidad del Estado para ejercer la custodia sobre éstas. El caso de México es relevante no sólo por tener uno de los conflictos internos más violentos del mundo, sino por haber sido importante receptor de armas provenientes de Estados Unidos y Alemania desde hace varias décadas.

Proponemos, a modo de hipótesis, que la configuración de la política de exportación de armas de cada país es resultado de tres variables: el grado de interés de cada Estado en proteger su reputación internacional en una época en la que el marco normativo de los derechos humanos se impone como elemento categórico; la capacidad de la sociedad civil

7 Open Society Justice Initiative, Atrocidades innegables: confrontando crímenes de lesa humanidad en México, Nueva York, Open Society Foundations, 2016, pp. 14-17. 
para intervenir en la toma de decisiones sobre este tema y el poder relativo de la industria armamentista.

Como buscaremos mostrar a lo largo del artículo, estas variables no sólo explican la forma en que ambos países han ejecutado su política de control de exportación de armas en lo que respecta a México, sino también, en un plano más general, los límites en la edificación de su política de control de exportaciones a escala global.

El artículo se propone hacer contribuciones a dos debates académicos distintos: por un lado, el que inquiere en la forma en que actores no estatales (sociedad civil e industria) intervienen en el proceso de toma de decisiones en la política de exportación de armas; por otro lado, el interesado en examinar cómo las normas internacionales afectan el comportamiento y las prácticas de los Estados nacionales, un tema clave en la agenda constructivista de las relaciones internacionales. ${ }^{8}$

El primer debate tiene dos vertientes: por un lado, el estudio de cómo la industria armamentista se relaciona con las instituciones estatales para alcanzar sus intereses; por otro lado, el examen de las actividades de organizaciones no gubernamentales que presionan políticamente para limitar la exportación de salw. Ambas han sido poco atendidas, lo cual es claro por la escasa bibliografía. ${ }^{9}$ En relación con el segundo debate, a pesar de que el estudio de la vinculación entre seguridad nacional y la emergencia de normas internacionales se ha asumido como propio en la agenda constructivista, el tema de los controles de exportación de armas apenas se ha teorizado desde esta perspectiva. ${ }^{10}$

${ }^{8}$ A partir de la interpretación de: M. Finnemore y K. Sikkink, "International Norm Dynamics and Political Change", International Organization 52, núm. 4, 1998, pp. 887-917.

${ }^{9}$ Una notable excepción es: S. Grillot, C. S. Stapley y M. E. Hanna, “Assessing the Small Arms Movement: The Trials and Tribulations of a Transnational Network", Contemporary Security Policy 27, núm. 1, 2006, pp. 60-84.

${ }^{10}$ Una excepción es: D. Garcia, Small Arms and Security: New Emerging International Norms, Londres, Routledge, 2006. 
Aunque existen algunos estudios sobre Alemania y Estados Unidos como potencias exportadoras de SALW, no conocemos ningún trabajo que compare las políticas de exportación de dos países frente a un único país importador. Del mismo modo, la bibliografía sobre la exportación legal de armas a México es yerma. Esto, debido a que la investigación sobre desvío de armas y su relación con el comercio legal se ha concentrado en los así llamados "Estados frágiles" o con experiencias recientes de guerra civil u ocupación militar. ${ }^{11}$ A pesar de que la región adolece de la tasa de homicidios con armas de fuego más alta del mundo, América Latina no ha sido foco de atención de esta agenda de investigación. Por último, la bibliografía que trata el problema de la proliferación de armas en México se ha centrado casi con exclusividad en el tráfico ilegal de armas desde Estados Unidos, pero apenas ha analizado el fenómeno de las armas que, una vez que ingresan al país por la vía legal, terminan en manos de actores no estatales o actores estatales coludidos con redes criminales.

Además de la revisión de material oficial y de una extensa revisión bibliográfica, para la elaboración de esta investigación los autores efectuaron entrevistas con autoridades decisorias en Berlín, Washington D. c. y Ciudad de México entre 2011 y 2017.

El texto está dividido en cinco secciones. La primera parte presenta la relevancia de Estados Unidos y Alemania en tanto productores y exportadores de armas, un breve análisis del marco legal para el control de armas de ambos países, así como su posición frente a los múltiples intentos por crear un régimen de control de armas supranacional. La segunda sección analiza cómo el concepto de "derechos humanos" se ha integrado a las políticas de control de armas en los dos Estados. El tercer apartado examina, desde una perspectiva com-

${ }^{11}$ Véase, por ejemplo: M. Bromley et al., "Transfers of Small Arms and Light Weapons to Fragile States: Strengthening Oversight and Control", SIPRI, enero de 2013. 
parada, las leyes de control de armas en Estados Unidos y Alemania; se analizan sus características principales y se exploran sus principales problemas. En la cuarta parte se revisa el papel de México como importador de salw de origen alemán y estadounidense, y la forma en que estos dos páises han aplicado sus políticas de control de armas ante el conflicto en México. En la quinta sección se presentan las variables que explican las posiciones diferenciadas entre ambos países exportadores.

\section{Alemania y Estados Unidos: dos potencias EXPORTADORAS DE SALW FRENTE AL MULTILATERALISMO}

A lo largo de las últimas décadas, Estados Unidos y Alemania se han sostenido como dos potencias exportadoras de SALW a escala mundial: Estados Unidos en el primer sitio y Alemania en el tercero. ${ }^{12}$ Además, empresas de ambos países dominan el mercado de municiones, consumibles y componentes de SALW. ${ }^{13}$

En Estados Unidos se producen más sAlw que en cualquier otro lugar del planeta. Entre 1986 y 2015, cientos de empresas estadounidenses manufacturaron más de 143 millones de unidades. ${ }^{14}$ Esto es, una media de cuatro millones anuales. Aún más: en los cuatro últimos años de los que se tienen datos consolidados (2012-2015) el promedio anual de salw producidas fue de más de nueve millones. ${ }^{15}$

12 Small Arms Survey 2015: Weapons and the World, Cambridge, University Press, 2015, p. 4.

${ }^{13}$ O. Nassauer, "Hemmungslos in alle Welt: Die Munitionsexporte der Rheinmetall AG". Berliner Informationszentrum für Transatlantische Sicherheit, 2016.

${ }^{14}$ Bureau of Alcohol, Tobacco, Firearms and Explosives, "Firearms Commerce in the United States: Annual Statistical Update 2017", 2017, p. 1. En Estados Unidos, el concepto más usado es el de firearms y no salw. Por firearms -traducido por nosotros como "armas de fuego"- se contemplan pistolas, revólveres, escopetas y rifles.

${ }^{15}$ Loc. cit. 
Según el Bureau of Alcohol, Tobacco, Firearms, and Explosives (ATF), empresas estadounidenses exportaron entre 2012 y 2016 una media de 364000 armas al año, registrándose el pico en 2014 con 420000 armas exportadas. ${ }^{16}$ Al Registro Convencional de Armas de las Naciones Unidas (UNROCA), Estados Unidos reportó la exportación de 409348 armas cortas y ligeras. ${ }^{17}$ Alemania, por su parte, reportó a UNROCA poco más de 33000 armas cortas y ligeras exportadas en 2017, mucho menos de las 80993 exportadas en $2015 .{ }^{18}$ Más que la exportación de sALW, para la industria alemana es especialmente relevante el mercado de municiones, mismo que trajo ganancias de más de 1000 millones de euros en $2016 .{ }^{19}$ Un tema a explorar en relación a estos números es el desplazamiento de empresas alemanas de SALW a Estados Unidos en la búsqueda de jurisdicciones con marcos legales menos estrictos. Ello explica, al menos en parte, la tendencia a la baja de las exportaciones alemanas. ${ }^{20}$

${ }^{16}$ Las dos fuentes disponibles para acercarse a este fenómeno son el U.S. Census Bureau (USCB) y el ATF. Ambas organizaciones presentan bases de datos y metodologías distintas en sus informes sobre exportación de SALW: la primera se basa en informes aduanales, mientras la segunda lo hace a partir de los datos que recolecta de las empresas productoras. Además, mientras el reporte de ATF, el Annual Firearms Manufacturing and Exportation Report (AFMER), sólo contempla exportaciones civiles, el USCB incluye exportaciones militares. Por lo regular, y de manera continua al menos desde la década de los años ochenta, el UscB registra números notablemente más altos.

${ }^{17}$ Disponible en United Nations Register of Conventional Arms, UNROCA, Transparency in the global reported arms trade (sitio de internet), https:/ / www.unroca.org/: [consulta: 15 de junio de 2018]. 2016 es el único año en que Estados Unidos reportó directamente a UnRoca. Las cifras de otros años no son confiables.

18 Loc. cit

19 Bundesregierung, "Bericht der Bundesregierung über ihre Exportpolitik für konventionelle Rüstungsgüter im Jahr 2016”, 2017, p. 21.

${ }^{20} \mathrm{Al}$ respecto véase: C. A. Pérez Ricart y L. Ramhorst, "De Alemania a Estados Unidos: el desplazamiento de la producción de armas cortas y ligeras. Nuevas prácticas, viejos negocios", Agenda 12, México vía Berlín e. V., 2018. 
La magnitud del presupuesto del Departamento de Defensa y del mercado doméstico de armas en Estados Unidos provoca que su industria no sea dependiente de su capacidad exportadora. ${ }^{21}$ Aun así, ha sido históricamente uno de los países que mayor oposición ha mostrado a los esfuerzos internacionales por imponer un régimen común que regule la exportación de armas en lo general y de sALw en lo particular. Destaca su oposición al "Programa de Acción", adoptado en 2001 como resultado de la Conferencia de las Naciones Unidas sobre el Tráfico Ilícito de Armas Pequeñas y Ligeras en Todos sus Aspectos, así como la no suscripción -también en 2001- del Protocolo contra la Fabricación y el Tráfico Ilícitos de Armas de Fuego, sus Piezas y Componentes y Municiones que complementa la Convención de las Naciones Unidas contra la Delincuencia Organizada Transnacional. Igualmente, en 2015 fue rechazada por Estados Unidos una iniciativa para implementar un sistema vinculante de marcaje y localización de SALw. ${ }^{22}$ La cúspide del antagonismo estadounidense a una política multilateral de control de armas llegó en 2006, cuando su delegación ante la Asamblea General de la onv fue la única en votar en contra -entre 153 países- de autorizar a la onU el inicio del proceso de creación del Tratado sobre el Comercio de Armas (тсA o AтT por sus siglas en inglés). ${ }^{23}$

El caso alemán es diametralmente distinto. Alemania ha sido desde la posguerra un activo impulsor de acuerdos vincu-

${ }^{21}$ Véase M. Tracey, "Trump aiming to toss ailing gunmakers a lifeline worth millions", The Young Turks, 30 de abril de 2018, https://tytnet work.com

${ }^{22}$ Se trata del Instrumento Internacional para permitir a los Estados Identificar y Localizar, de Forma Oportuna y Fidedigna, Armas Pequeñas y Ligeras Ilícitas (APAL) aprobado en 2005 por la Asamblea General de Naciones Unidas.

${ }^{23}$ Después de buscar cambios que debilitaran el texto, la administración de Obama firmó el ATT (TCA por sus siglas en español). Aun así, el Congreso de Estados Unidos aún no ha ratificado el tratado. Al respecto, véase J. L. Erickson, "Saint or Sinner? Human Rights and U.S. Support for the Arms Trade Treaty", Political Science Quarterly 130, núm. 3, 2015, p. 457. 
lantes que regulen la exportación de armas. ${ }^{24}$ Así por ejemplo, fue uno de los principales promotores en agregar, en 2003, la categoría SALw a la lista de productos militares cuyo destino deben reportar los países parte del Wassenaar Arrangement (WA), un acuerdo no vinculante firmado en 1996 en el que 42 países se comprometen a intercambiar información acerca de sus exportaciones de armas no convencionales. Asimismo, propuso una guía de buenas prácticas que limitaran el acceso a armas y municiones a grupos no estatales. En el marco de su membresía al wa, Alemania ha buscado imponer el criterio de derechos humanos como indispensable para el otorgamiento de permisos de exportación, así como difundir su modelo de regulación a países que no sean parte del wA. ${ }^{25}$ De forma similar, Alemania promovió, entre otras iniciativas, el ya mencionado "Programa de Acción” de Naciones Unidas en 2001 y los esfuerzos por generar un estricto marco normativo sobre la exportación de SALW para la Organización para la Seguridad y la Cooperación en Europa (osce). Por último, Alemania no solamente ya firmó y ratificó el TCA, también fue impulsor -y es país donador- del Servicio Fiduciario de Apoyo a la Cooperación para la Regulación de los Armamentos, una herramienta del tratado para apoyar a otros Estados a poner en funcionamiento el TCA, el cual ya firmó y ratificó también México.

Más adelante intentaremos explicar por qué dos países exportadores de SALW mantienen posiciones tan diferenciadas en torno a las pautas que deben regir los sistemas de regulación globales. Antes de ello, sin embargo, se revisarán las políticas de control de armas en Alemania y Estados Unidos, así como la forma en que cada país adoptó, o no, una perspectiva de derechos humanos.

${ }^{24}$ Bundesregierung, art. cit., p. 12.

25 Ibid, p. 13. 
LOS DERECHOS HUMANOS EN LAS POLÍTICAS DE CONTROL DE aRmas EN Estados Unidos y Alemania

\section{Estados Unidos}

La idea de que los derechos humanos deben ser un criterio relevante para la expedición de permisos de exportación de armas ha tenido una ruta problemática en la legislación estadounidense.

La Presidential Directive (PD-13), promulgada en 1977 por Jimmy Carter, señala la violación a los derechos humanos como criterio a considerar en el proceso de toma de decisiones con respecto a la autorización de licencias y acuerdos. Ese mismo año, como parte de una reforma a la Foreign Assistance Act (FAA) de 1961, el Congreso estadounidense legisló en contra de la prestación de servicios militares a gobiernos que practiquen violaciones a los derechos humanos. Ya en 1976, el presidente Ford había promulgado la Arms Export Control Act (AECA), ley que aún hoy regula los límites y alcances de la exportación de armas desde Estados Unidos. La AECA no incluye nada relativo a los derechos humanos, pero señala que cualquier decisión de exportación legal de armas debe tomar en cuenta si los productos exportados contribuirán a una carrera armamentista, al desarrollo de armas de destrucción masiva o a escalar situaciones de conflicto. ${ }^{26}$

Esa primera ola de política de exportación de armas "responsable" tuvo un freno con la llegada a la presidencia de Ronald Reagan, quien apeló a una política de exportación de armas pragmática y mucho más cercana al así llamado realismo político. De este modo, durante la década de los años ochenta y en el marco de la Guerra Fría, mediante operaciones encubiertas, los servicios de inteligencia de Estados Unidos dotaron de millones de armas a grupos insurgentes en Centroamérica y Asia; solamente en Afganistán se calcula en tres millones el número de fusiles AK-47 exportados con

26 22. U.S.C. $§ 2778$. 
la ayuda de la cIA a los muyahidines en su enfrentamiento contra la ocupación soviética. ${ }^{27}$

Las consideraciones de derechos humanos en la toma de decisiones de política de control de exportación de armas volvieron a plasmarse en un documento oficial en febrero de 1995, con la publicación de la Presidential Decision Directive número 34 de Bill Clinton (PDD-34). Junto a otros once "criterios generales" -entre otros, el impacto comercial de cada venta en la industria o los intereses regionales de Estados Unidos- se estipuló que "los derechos humanos, el terrorismo, el historial de proliferación del importador y el potencial mal uso de la exportación en cuestión" serían tomados en cuenta para la toma de decisiones. ${ }^{28}$ Sin embargo, a diferencia de lo acontecido durante la presidencia de Carter, en la práctica no se limitó el arco de países receptores de armamento estadounidense.

En 1997 se introdujo la Ley Leahy en la legislación estadounidense - en referencia a su autor, el senador demócrata Patrick Leahy- que prohíbe dar asistencia a cualquier unidad militar o policial en el extranjero si el Departamento de Estado cuenta con información fehaciente de que miembros de esa unidad han cometido violaciones graves de los derechos humanos y de que no han sido procesados judicialmente. Aunque es limitada en su alcance, la Ley Leahy no es discrecional y ha sido invocada para negar asistencia a muchas unidades de distintos países, incluyendo México. ${ }^{29}$ Sin embargo, no se aplica a exportaciones directas de armamento y se refiere únicamente a tareas de asistencia y cooperación militar.

${ }^{27}$ J. Boutwell y M. Klare, "Small Arms and Light Weapons: Controlling the Real Instruments of War”, Arms Control Today 28, núm. 6, 1998, p. 18.

28 The White House Office of the Press Secretary, "Presidential Policy Directive 34: United States Conventional Arms Transfer Policy”, 1995.

${ }^{29}$ Véase: J. Franzblau y C. Currier, "Mexican authorities implicated in violence, but U.S. security aid still flows", The Intercept, 8 de mayo de 2015, https://theintercept.com 
Si bien George W. Bush mantuvo inalterada la PDD-34 y la Ley Leahy, durante su administración predominó una concepción pragmática del control de armas muy similar a la de Ronald Reagan. Durante su mandato se presentaron al menos dos acontecimientos importantes: la autorización en 2004 de transferencias de armas y municiones a Ruanda (en ese entonces bajo embargo parcial de armas) y la exportación en 2007, sin ningún protocolo de transparencia, de cientos de miles de pistolas, rifles de asalto y pistolas automáticas a las fuerzas de seguridad iraquíes. ${ }^{30}$

A principios de 2014, el presidente Barack Obama firmó la Presidential Policy Directive número 27 (PPD-27), que reemplaza la directiva de 1995. Se trata del producto final de un proceso efectuado entre varias agencias del poder ejecutivo. ${ }^{31}$ A primera vista, los cambios entre la directiva de 2014 y la de 1995 son meramente cosméticos. Sin embargo, la PPD-27 incluye dos modificaciones importantes respecto a los criterios a tomar en cuenta para aprobar o denegar permisos de exportación. Por un lado, se menciona el riesgo de que un cambio en la situación política o de seguridad del país importador pueda llevar a un uso inapropiado de las armas transferidas. Por otro, la posibilidad de que el receptor de las armas las utilice para perpetrar abusos a los derechos humanos o violaciones al derecho internacional. La inclusión de ambas consideraciones refleja el debate acontecido los meses posteriores a la Primavera Árabe en 2011 y el temor de reconfiguraciones políticas en Medio Oriente. Con todo, en la PPD-27 los derechos humanos apenas son una de las diez consideraciones no prioritarias a tomar en cuenta para el otorgamiento o negación de permisos de exportación. Prueba de su poca relevancia es la tendencia al alta de las exportaciones de salw desde su expedición.

${ }^{30}$ S. Waltz, "US Policy on Small Arms Transfers: A Human Rights Perspective", Human Righs Eं Human Welfare Working Paper, 43, 2007, p. 4.

31 The White House Office of the Press Secretary, "Presidential Policy Directive 27: United States Conventional Arms Transfer Policy”, 2014. 
En resumen, en la práctica, y a pesar de contar con algunas referencias en el conjunto de documentos que guían su política de armas, la protección de derechos humanos no es ni ha sido un criterio prioritario para obstruir ventas directas de armamento. Al igual que durante la Guerra Fría, en la toma de decisiones sobre políticas de control de exportación de armas en Estados Unidos prevalecen consideraciones de "seguridad nacional" y el interés por beneficiar a la industria. ${ }^{32}$ Por lo demás, en el futuro solamente se prefiguran retrocesos en este renglón: Donald Trump recientemente reemplazó la PPD-27 con un nuevo memorándum presidencial en el que se ensalza "la seguridad económica" como factor predominante de su política de exportación. ${ }^{33}$

\section{Alemania}

Aunque los derechos humanos no aparecen como criterio para aprobar o no un permiso de exportación hasta el año 2000, desde la posguerra Alemania ha utilizado los adjetivos "restrictiva" y "responsable" (restriktive und verantwortungsvolle Rüstungsexportpolitik) para definir su política de exportación de armas. Contrario a lo que sucede en Estados Unidos, el tema ha despertado históricamente el interés y la sensibilidad en la sociedad alemana. Es probable que esto sea una respuesta a la cercana relación entre la industria armamentista y el nacionalsocialismo entre 1933 y $1945 .^{34}$

Si bien en 1954 se reinició la exportación de armamento alemán -cuyos primeros receptores fueron Ecuador e Indo-

${ }^{32}$ Erickson, "Saint or Sinner? ...", art. cit., p. 454.

33 D. J. Trump, "National Security Presidential Memorandum Regarding U.S. Conventional Arms Transfer Policy”, 19 de abril de 2018. Para un análisis: J. Abramson, "Trump Favors Arms Industry in Effort to Loosen Export Controls", Arms Control Association, Issue Briefs 10, núm. 6, 2018, pp. 1-6.

${ }^{34}$ M. Brzoska, "The Erosion of Restraint in West German Arms Transfer Policy”, Journal of Peace Research 26, núm. 2, 1989, pp. 165-177. 
nesia- no fue hasta 1965 que se estableció la figura de Spannungsgebiet o zona de conflicto como elemento a considerar para la concesión de permisos de exportación. El principio era muy sencillo: las armas alemanas no deberían atizar la violencia en regiones conflictivas. Con la llegada del Partido Social Demócrata (SPD) al gobierno, en 1969, se aprobaron una serie de directrices políticas en favor de limitar las exportaciones de armas a países del así llamado Tercer Mundo - un tema con el que el spo hizo campaña electoral. Sin embargo, fricciones en la coalición gobernante llevaron a una progresiva relajación de controles que, a su vez, condujeron a un pico en las exportaciones de armas alemanas a mediados de la década de los años setenta. ${ }^{35}$

En 1982, el Partido Demócrata Cristiano (CDU) determinó eliminar la cláusula del Spannungsgebiet y reemplazarla por la de "interés vital" (vitale Interessen der Bundesrepublik Deutschland) como consideración central para la aprobación o no de exportaciones a países fuera de la OTAN. ${ }^{36}$ Con todo, sin embargo, el "interés vital" debía interpretarse desde una dimensión política o de seguridad, no económica o asociada a la protección de la industria. ${ }^{37}$ Por lo demás, los Politische Grundsätze der Bundesregierung für den Export von Kriegswaffen und sonstigen Rüstungsgütern -el documento base del gobierno federal que regulaba ya entonces la exportación de armamento- refería que debía evitarse la exportación de armamento alemán a regiones en conflicto, una preocupación ausente en la mayoría de las legislaciones europeas de ese momento. ${ }^{38}$

En 2000, una reforma al mismo documento incluyó que la sospecha (hinreichende Verdacht) de que material de guerra

35 Sobre la historia de la política de exportación en Alemania, véase: M. Brzoska, A. A. Guha y C. Wellmann, Das Geschäft mit dem Tod: Fakten und Hintergründe der Rüstungsindustrie, Frankfurt, Eichborn Verlag, 1982, pp. 10-15.

36 Bundesregierung, "Politische Grundsätze der Bundesregierung für den Export von Kriegswaffen und sonstigen Rüstungsgütern”, Bulletin des Presse-und Informationsamtes der Bundesregierung 38, 1982, pp. 309.

${ }^{37}$ Brzoska, "The Erosion of Restraint ...", art. cit., p. 171.

38 Ibid, p. 172. 
pudiera utilizarse para prácticas represivas o para el abuso de los derechos humanos es un elemento suficiente para rechazar cualquier transacción armamentista. ${ }^{39}$ Tal cláusula continúa activa y obliga a que todo acuerdo de exportación se acompañe de un examen preciso de la situación de los derechos humanos en el país receptor. Para ello, el gobierno alemán se compromete a tomar reportes de organizaciones no gubernamentales y estudios de los órganos competentes de Naciones Unidas y la Unión Europea. El equivalente a esa cláusula en la legislación estadounidense es el risk assessment requirement de AECA: un dispositivo difuso y sin apenas dientes.

En resumen, aunque el concepto es relativamente nuevo, desde la posguerra ha imperado, al menos en el discurso, la idea de que la política de control de armas debe ser "restrictiva" y guiada por una noción de derechos humanos. Aun cuando ello no ha evitado el arribo de material alemán a zonas en conflicto, hay consenso de que Alemania aún tiene uno de los sistemas regulatorios de control de armas que más ha considerado una dimensión de derechos humanos.

\section{LEYES Y POLÍTICAS DE CONTROL DE ARMAS}

En la bibliografía especializada suele aceptarse la noción de que Estados Unidos tiene uno de los sistemas de control de exportaciones de armas más estrictos y elaborados. Creemos que esta impresión nace de la escasez de estudios comparados y de la lectura acrítica que se ha hecho de la narrativa que enarbolan los funcionarios del Departamento de Estado y del Departamento de Defensa respecto al tema.

Así por ejemplo, se ha llegado a señalar que Estados Unidos tiene "algunas de las mejores leyes y regulaciones sobre

39 Bundesregierung, "Politische Grundsätze der Bundesregierung für den Export von Kriegswaffen und sonstigen Rüstungsgütern”, 2000. 
control de armas pequeñas y ligeras en el mundo". ${ }^{40}$ Rachel Stohl, en particular, ha afirmado que Estados Unidos ha "impuesto estándares en los temas de control de exportación legal de armas, control de usuario final y corretaje de armas". ${ }^{41}$ Según la autora, el rechazo estadounidense a controles internacionales más severos se explica en tanto que "sus propias leyes exceden por mucho la norma internacional". ${ }^{42}$ Estos comentarios van en consonancia con la idea gubernamental de que Estados Unidos impone "las leyes más robustas y efectivas del mundo [...] el gold standard de los controles internacionales". ${ }^{43}$

Conclusiones similares pueden leerse en textos publicados en revistas especializadas y por autores a quienes no se les puede imputar falta de independencia. ${ }^{44}$ A diferencia de estas consideraciones, creemos que la política de control de armas de Estados Unidos necesita volver a problematizarse tomando como base estudios comparados. Para ello, a continuación, reseñaremos sus principales características y señalaremos las que consideramos sus principales deficiencias. Más adelante, haremos lo mismo con el sistema alemán.

Estados Unidos: ¿el gold standard del control de exportaciones de armas?

La exportación de productos y servicios militares en Estados Unidos está reglamentada en el Code of Federal Regu-

${ }^{40}$ R. Stohl, "United States weakens outcome of UN Small Arms and Light Weapons", Arms Control Association, 1 de septiembre de 2001, https://www.armscontrol.org

${ }^{41}$ Loc. cit.

${ }^{42}$ Loc. cit. 2006.

${ }^{43}$ J. Hillen, "Small Arms, Big Danger", The Baltimore Sun, 3 de julio de

${ }^{44}$ Véase, por ejemplo: Grillot, "Global Gun Control: Examining the Consequences...”, art. cit., p. 543. 
lations, CFR (Código de Regulaciones Federales) de Estados Unidos. Tanto los procedimientos administrativos como la lista de productos sujetos a permisos especiales están en el CFR y se conocen como International Traffic in Arms Regulations (ITAR) ${ }^{45}$ Además de las disposiciones del ITAR, la legislación federal de Estados Unidos contempla lo estipulado en AECA, así como en FAA (véase supra).

Empresas estadounidenses exportan SALW de manera legal mediante dos mecanismos principales: ventas comerciales directas entre una empresa determinada y un comprador, que puede o no ser estatal (Direct Commercial Sales, DCS) y acuerdos directos entre el Departamento de Defensa y alguna entidad de otro gobierno (Foreign Military Sales, FMS). A continuación, sólo nos centraremos en el análisis de DCs, dimensión que atañe mayoritariamente nuestro caso de estudio.

En el diseño, ejecución y evaluación de política de control de exportación de salw a partir del esquema DCS participan unas veinte agencias distintas del gobierno de Estados Unidos. ${ }^{46}$ No todas tienen ni representan los mismos intereses, ni inciden de la misma manera en la toma de decisiones. Incluso, en una misma dependencia, como el Departamento de Estado, interactúan oficinas con intereses diferenciados y a menudo antagónicos. Para entenderlo mejor presentaremos una breve descripción del proceso de transferencia de SALw. ${ }^{47}$

Para ser concretos, toda DCs debe estar precedida por la expedición de un permiso de exportación a cargo del Departamento de Estado; específicamente, del Directorate of

45 Título 22, volumen 1, capítulo 1, subcapítulo M, partes 120 a 130 del CFR.

46 Waltz, art. cit., p. 11.

47 Cabe señalar que este proceso está sujeto a una posible modificación en el corto plazo. Así lo ha anunciado la administración Trump. Según se ha señalado, la responsabilidad en temas de control de algunas exportaciones se transferiría del Departamento de Estado al Departamento de Comercio. 
Defense Trade Controls (DDTC) establecido en el Bureau of Political-Military Affairs (PM). La empresa interesada debe registrarse ante esta oficina y solicitar formalmente el permiso de exportación. Entre los muchos registros a completar, debe especificarse el tipo de producto que pretende exportarse, el marco temporal en el que se llevaría a cabo la operación y los usuarios finales, así como el valor estimado del acuerdo. Por lo general, una vez sometida a revisión la solicitud, el proceso debe finiquitarse en menos de sesenta días. ${ }^{48}$

El DDTC debe deliberar junto con otras oficinas del Departamento de Estado, así como con otras agencias federales, sobre la conveniencia o no de otorgar el permiso de exportación. En principio, el DDTC debe atender los criterios generales establecidos en las directivas presidenciales vigentes (véase supra) y tomar en cuenta las consideraciones expresadas por la representación regional del Departamento de Estado correspondiente al país receptor -en el caso de México y América Latina, el Bureau of Western Hemisphere Affairs (WHA)-, así como del Bureau of Democracy, Human Rights and Labor (DRL), otro organismo del Departamento de Estado. Sin embargo, a pesar de ser parte del proceso, el DRL no cuenta con autoridad estatutaria para frenar un acuerdo comercial de armas por consideraciones de derechos humanos. ${ }^{49}$

Además de las fuertes presiones a las que está expuesto, el DDTC no cuenta con la capacidad operativa para valorar estrictamente cada una de las peticiones de exportación. Se trata de una oficina que en 2015 contaba solamente con 80 empleados, 64 contratistas, ocho militares y dos agentes

${ }^{48}$ State Department Office of Defense Trade Controls, "Guidelines for preparing agreements", 2016, http://www.pmddtc.state.gov/licen sing/agreement.html.

${ }^{49}$ Center for Civilians in Conflict y Stimson Center, "With great Power: Modifying US Arms Sales to Reduce Civilian Harm”, 2018, pp. 18-20. 
de enlace con otros departamentos. ${ }^{50}$ En los últimos años, su capacidad operativa se ha ido reduciendo aún más. ${ }^{51}$

Además de la poca autonomía y capacidad operativa del DDTC para valorar cada una de las peticiones de exportación, un tema crucial es la ausencia de un marco legal que lo obligue a utilizar herramientas más estrictas para identificar los perfiles de los usuarios finales de cada exportación. Un ejemplo de esto es la no obligatoriedad del DDTC de utilizar el Rastreo de Revisión Internacional y Seguridad (International Vetting and Security Tracking, Invest), un sistema utilizado por el DRL para vetar posibles receptores de asistencia y equipo militar. El Invest fue creado para aplicar la Ley Leahy; se trata de una base de datos para identificar unidades militares con récords negativos en el respeto a los derechos humanos. ${ }^{52}$ En lugar de utilizar el complejo sistema Invest para la expedición de permisos DCS, el Departamento de Estado trabajaba -por lo menos en mayo de 2017- exclusivamente con una "Watch List" que sólo registra unidades receptoras de productos o servicios militares alrededor del mundo. El fracaso de ese instrumento se materializa en un hecho difícil de controvertir: para otorgar permisos, el Departamento de Estado no discrimina entre clientes provenientes de regiones en conflicto o con déficits en materia de derechos humanos. ${ }^{53}$

Es una práctica común que los países exportadores de SALW tengan un programa de control de usuarios últimos.

50 Bureau of Political-Military Affairs Directorate of Defense Trade Controls State Department, "End-Use Monitoring of Defense Articles and Defense Services Commercial Exports FY 2015”, 2016, p. 1, http:// pmddtc.state.gov

${ }^{51}$ La lista de funcionarios puede verse en: U.S. Department of State. Directorate of Defense Controls, http:/ / pmddtc.state.gov.

${ }^{52}$ M. McNerney et al., "Improving Implementation of the Department of Defense Leahy Law”, RAND Corporation, 2017.

53 Véase: T. Thrall y C. Dorminey, "Risky Business: The Role of Arms Sales in U.S. Foreign Policy”, Policy Analysis, Cato Institute, marzo de 2018, pp. 4-6. 
Esto es, un sistema de monitoreo que garantice que la unidad importadora -en tanto usuario final del producto- cumpla con los requerimientos impuestos con respecto al uso, transferencia y seguridad de los artículos y servicios importados. En Estados Unidos ese programa, fundado en 1990, es conocido como Blue Lantern y su funcionamiento recae en el DDTC. Para mayor especificidad, de una de sus oficinas con seis empleados y tres contratistas: la Regional Affairs and Analysis Division (RAA).

Aunque la creación de Blue Lantern significó un avance importante en los esfuerzos de monitoreo de usuarios finales en Estados Unidos, carece todavía de recursos suficientes para efectuar una verificación real de una parte representativa del total de las licencias que expide anualmente el DDTC. Así por ejemplo, en 2015 solamente 1\% de todas las licencias de exportación estuvo sujeta a verificaciones: 570 de 44103 permisos de exportación otorgados. ${ }^{54}$

Según la RAA, los monitoreos de Blue Lantern no son aleatorios; se priorizan las inspecciones a socios "poco comunes", a material de guerra especialmente "sensible" y a rutas comerciales "inusuales". ${ }^{55}$ Ello explicaría el alto porcentaje de muestras desfavorables: 26\% en 2015. ¿Qué significa que el monitoreo Blue Lantern sea desfavorable? Que la distribución del material de guerra o su uso no son congruentes con los términos en los que se concedieron los permisos. Las razones pueden ser varias: falta de medidas de seguridad en el resguardo de material, participantes sospechosos en las cadenas de custodia, pruebas de reventa de los productos a intermediarios o simplemente rechazo a cooperar con la RAA en los monitoreos. En lo que nos parece una omisión fundamental, las revisiones de Blue Lantern no contemplan una categoría que refleje el uso inapropiado del arma en actos de

${ }^{54}$ Directorate of Defense Trade Controls, "End-Use Monitoring of Defense Articles and Defense Services Commercial Exports FY 2015", p. 2. ${ }^{55} \mathrm{Ibid}, 3$. 
violación a derechos humanos. ${ }^{56}$ En defensa del sistema de control de Estados Unidos, siempre puede argumentarse que la escala de productos exportados es de tal tamaño que hace extremadamente difícil la aplicación de controles efectivos.

Otro de los ejes que llevan a pensar que el sistema estadounidense está lejos de ser el gold standard de los controles de exportación de armas es el limitado margen de maniobra que tiene el Congreso para intervenir respecto a esto. Si bien es cierto que los acuerdos de exportación de SALW (y otras armas convencionales) a países fuera de la OTAN, y superiores al millón de dólares, deben notificarse al Congreso con 30 días de anticipación antes del cierre de cada contrato, la suspensión o negación de una licencia como resultado de una revisión de esta índole se da sólo en casos excepcionales. Además, en última instancia, cualquier oposición está sujeta al veto presidencial. ${ }^{57}$

Fuera de los acuerdos habituales, consideraciones de seguridad nacional pueden justificar la puesta en práctica de operaciones encubiertas de transferencia de salw. Se trata de exportaciones sin monitoreo ni registros internacionales ${ }^{58}$ que suceden casi siempre amparadas en la National Security Act (50 U. S. Code). En su subcapítulo III (\$415) se legaliza la transferencia de armas y otros productos militares como posible estrategia para el ejercicio de influencia política, económica o militar fuera de Estados Unidos. ${ }^{59}$ Otra ley otorga al presidente de ese país la facultad de solicitar a miembros

${ }^{56}$ Center for Civilians in Conflict y Stimson Center, op. cit., p. 24.

${ }^{57}$ Para una discusión sobre el papel del Congreso de Estados Unidos a este respecto, véase P. K. Kerr, "Arms Sales: Congressional Review Process”, Congressional Research Service, julio de 2017. Véase también Center for Civilians in Conflict y Stimson Center, ibid, p. 28.

${ }^{58}$ Waltz, art. cit., p. 11, 13-14. Véase también Special Inspector General for Iraq y Reconstruction, "Iraqi Security Forces: Weapons Provided by The U.S. Department of Defense Using the Iraq Relief and Reconstruction Fund", Virginia, 2006, pp. 10-11. Para el caso de una exportación ilegal vía Bosnia Herzegovina rumbo a Ruanda, véase Amnesty International, "Democratic Republic of Congo: Arming the East", 2005, pp. 29-31.

59 Waltz, ibid, p. 12. 
de las fuerzas armadas que alienten y promuevan la compra de equipo armamentista por un gobierno extranjero. ${ }^{60}$

A todo este conjunto de transferencias de armas que no están ni en la categoría de "operaciones encubiertas", pero que tampoco siguen los principios rectores de la política de regulación de exportación de armamento, Susan Waltz las llama "shadow transfers". Según su análisis, este tipo de prácticas no suponen una excepción a la política de control de armas, sino parte fundamental de su funcionamiento ${ }^{61} \mathrm{En}$ consecuencia, los reportes de Estados Unidos sobre transferencias de SALW y otros productos militares a los organismos internacionales suele ser opaco y deficitario. ${ }^{62}$

En conclusión, la impronta de la doctrina de seguridad nacional todavía es visible en el sistema regulatorio de exportación de armas estadounidense. La industria armamentista se beneficia de esto y exporta a tal escala que vuelve compleja y dificulta los controles efectivos. Más todavía, la exportación de armas continúa siendo parte integral de la política exterior estadounidense. Así las cosas, la idea del perfecto funcionamiento del sistema de control de exportación de armas no es sino un "mito reconfortante". ${ }^{3}$

\section{Alemania: un sistema modelo con imperfecciones}

El ya referido Politische Grundsätze... constituye el documento central del sistema de control de exportaciones de armas alemanas. Además de éste, la Ley de Control de Armas (Kriegswaffenkontrollgesetz, KWKG) ${ }^{64}$ regula desde 1961 la

6022 USC $\$ 2321 \mathrm{i}(\mathrm{f})$.

61 Waltz, art. cit., p. 11.

62 P. D. Wezeman y S. T. Wezeman, "The 2015 UN Register on Conventional Arms: Still Time to Improve”, sIPRI, 18 de septiembre de 2015.

${ }^{63}$ W. D. Hartung, "U.S. Conventional Arms Transfers: Promoting Stability or Fueling Conflict?”, Arms Control Today 25, núm. 9, noviembre de 1995, p. 9.

${ }^{64}$ Ausführungsgesetz zu Artikel 26 Abs. 2 des Grundgesetzes. 
producción, comercio y uso de exportación de armas de guerra, las llamadas Kriegswaffen. Aunque establece la prohibición de la exportación de armas en lo general, concede al Ministerio Federal de Economía y Tecnología (Bundesministerium für Wirtschaft und Technologie, Bmwi) la facultad de otorgar, en acuerdo con el Ministerio de Relaciones Exteriores (Auswärtiges amt), permisos de exportación en casos excepcionales.

Además de la KwKG, la exportación de armas está sujeta a la Ley de Transacciones Internacionales (Außenwirtschaftsgesetz, AWG), que regula el intercambio de mercancías, servicios, capitales y pagos de Alemania con el resto del mundo. Así, cualquier transacción de armamento debe ser aprobada también por el Bundesamt für Wirtschaft und Ausfuhrskontrolle (BAFA), institución encargada del cumplimiento de la AWG. Las decisiones sobre exportaciones de armas, incluyendo SALW, a zonas sensibles, no las toman directamente los funcionarios del BAFA o del BMwi, sino el Bundessicherheitsrat (BSR), una comisión interagencial integrada por nueve políticos de máxima relevancia, incluyendo la figura del canciller, el ministro del exterior y el ministro de defensa. Lo anterior provoca que aumente el costo político del otorgamiento de permisos. Si bien las actas de discusión del BsR están clasificadas, sus decisiones finales son siempre públicas y materia de escrutinio público. Aunque deben explicarse ante el parlamento, éste no tiene forma de apelar las decisiones del BSR.

En tanto parte constitutiva de la Unión Europea, Alemania está sujeta a la Posición común del Consejo de la Unión Europea. ${ }^{65}$ Suscrita en 2008, establece ocho criterios según los cuales todos los países de la Unión Europea deberán "evitar la exportación de tecnología y equipos militares que pudieran utilizarse para la represión interna o la agresión internacional o contribuir a la inestabilidad regional". ${ }^{66}$ Especialmente rele-

${ }^{65}$ En adelante "Posición Común Europea".

66 "Posición común 2008/944/PESC del Consejo por la que se definen las normas comunes que rigen el control de las exportaciones de 
vante es el tercer criterio en el que se especifica que se negarán "licencias de exportación de tecnología o equipos militares que provoquen o prolonguen conflictos armados o que agraven las tensiones o los conflictos existentes en el país de destino final". ${ }^{67}$ La Posición común europea no interviene en el derecho de los Estados miembros para establecer normas nacionales más estrictas: se trata de un conjunto de pautas mínimas que establece mecanismos básicos de transparencia y monitoreo. En todo caso, resulta importante señalar que, al tener Alemania un marco legal mucho más riguroso que el establecido en la Posición común europea -y en el ATT-, son las leyes nacionales las que adquieren verdadera relevancia en tanto marcos de disputa para los promotores de controles más estrictos a la exportación de armamento.

Desde el año 2000, el gobierno alemán publica un informe anual que resume pormenorizadamente el valor de los productos y servicios militares exportados por parte de empresas alemanas, así como el país de destino (Bericht der Bundesregierung über ihre Exportpolitik für konventionelle Rüstungsgüter). Desde entonces, el informe se ha vuelto cada vez más completo. En 2014 comenzó a publicarse de forma semestral. Si bien sigue mostrando problemas, su sola publicación provoca que el tema vuelva a la luz pública al menos una vez por semestre y que el gobierno justifique públicamente el motivo de ciertas decisiones. Además, por ley, el MBwi debe contestar, por escrito y sin mayor dilación, los cuestionamientos públicos que realizan los partidos políticos sobre cada expedición de permisos. Otra notable diferencia es que Alemania sí reporta a UNROca de forma separada y voluntaria sus exportaciones de SALW.

En 2016, de forma extraordinaria, el MBwi lanzó una convocatoria para iniciar un proceso de consulta en torno al futuro de la política armamentista en Alemania, a la que se invitó

tecnología y equipos militares", Diario Oficial de la Unión Europea, 8 de diciembre de 2008. Las cursivas son nuestras.

${ }^{67}$ Loc. cit. 
a representantes de la Iglesia, la sociedad civil, los sindicatos y la industria. A partir de los comentarios vertidos en cinco mesas de debate diferentes, el MBwi se comprometió a revisar los temas más críticos del proceso de exportaciones; entre otros, la hasta ahora limitada participación del poder legislativo en la toma de decisiones. Cuando escribimos estas líneas continúa siendo incierto el resultado concreto de las deliberaciones.

El Kontrolle des Endverbleib, o identificación y control de usuario último, ha funcionado históricamente como la línea de defensa argumentativa sobre la exportación de armas en Alemania. Su incumplimiento castiga a la empresa exportadora con la detención inmediata de futuros permisos de exportación. ${ }^{68}$ A pesar de ello, es larga la lista de veces que no se ha cumplido. ${ }^{69}$ Para evitar su quebranto, en julio de 2015 comenzó a implementarse un programa piloto para supervisar el cumplimiento de las cláusulas de usuario final de productos y servicios militares. La instancia encargada de su ejecución es BAFA que, en cooperación con la representación alemana en el país importador -normalmente la embajadarealiza una serie de controles similares a los del Blue Lantern. Las primeras inspecciones de este programa piloto tuvieron lugar en mayo 2017 y por tanto es pronto para hacer diagnósticos sobre su efectividad.

Tras años de crítica por parte de organizaciones de derechos humanos y del movimiento pacifista en Alemania, en marzo de 2015 se aprobaron nuevas disposiciones para constreñir la exportación de sALw, así como sus componentes y consumibles (Kleinwaffengrundsätze). Entre otras medidas relevantes, se prohíbe la exportación de tecnología y componentes a países fuera de la OTAN y de la Unión Europea que tenga la finalidad de abrir "nuevas líneas de producción" (neue Herstellungslinien) de SALw y municiones. La ley de 2015

68 Bundesregierung, "Politische Grundsätze der Bundesregierung für den Export von Kriegswaffen und sonstigen Rüstungsgütern”, 2000, cap. Iv.3.A.

${ }^{69}$ Véase J. Grässlin, Schwarzbuch Waffen Handel: Wie Deutschland am Krieg verdient, Múnich, Heyne, 2013. 
estableció también la obligación a los países importadores de destruir sus armas viejas al comprar nuevas (Exportgrundsatz Neu für $A l t$ ). En los casos en que se justifique un aumento del arsenal de armas y por tanto resulte inconveniente la destrucción de armas viejas, la ley contempla la opción de obligar al país importador a destruir los nuevos productos antes de comprar una nueva tanda de armamento (Neu, Vernichtung bei Aussonderung). Alemania no sólo se ha comprometido a aplicar estas leyes, sino a impulsar su aplicación a escala europea. ${ }^{70}$ Esta intención puede leerse de dos maneras (y probablemente las dos lecturas sean correctas): por un lado, a partir de una auténtica preocupación por promover una política de regulación paneuropea de exportación de armas más responsable; por otro, como una forma de reducir la ventaja competitiva que tienen otras empresas europeas sobre las alemanas.

\section{LA SITUACIÓN MEXICANA Y LA RESPUESTA}

DE LA POLÍTICA DE EXPORTACIÓN DE ARMAS de Estados Unidos y Alemania

Una vez analizadas las principales diferencias entre los sistemas de exportación de armas en Estados Unidos y Alemania, queda responder a la pregunta sobre la forma en que ambos países han reaccionado frente a la crisis de derechos humanos en México. Para ello, primero se contextualizará el caso mexicano a la luz de la discusión sobre políticas de exportación de armas y derechos humanos.

\section{México: un caso problemático}

Identificamos cuatro ejes que tornan problemática la exportación de SALW a México: 1) la gran cantidad y proporción

70 Bundesregierung, "Bericht der Bundesregierung über ihre Exportpolitik für konventionelle Rüstungsgüter im Jahr 2016”, p. 6. 
de homicidios cometidos con armas de fuego; 2) la probada colusión entre autoridades estatales y criminalidad organizada; 3) el uso de salw en casos de violación a los derechos humanos por parte de agentes estatales; 4) la ausencia de controles confiables de armas. A continuación, trataremos brevemente cada una de estas dimensiones; más adelante analizaremos las consecuencias que tienen en relación con las políticas de regulación de exportación de armamento en Estados Unidos y Alemania.

Las altas tasas de violencia en México, y en particular de homicidios cometidos con armas de fuego, coloca al conflicto en México como uno de los diez más letales en el mundo. ${ }^{71}$ Es natural, por tanto, que la violencia sea una variable a considerar en la forma en que los países exportadores se relacionan con este país. El crecimiento constante de homicidios dolosos cometidos con SALW es especialmente preocupante: si en 2001 se abrieron unas 3500 carpetas de investigación por este delito, en 2017 fueron $16898 .^{72}$ La relevancia del uso de armas en homicidios dolosos ha aumentado, por lo demás, de forma desproporcionada: en 1997, 15\% de los homicidios se cometían con armas de fuego; veinte años más tarde, en 2007, la cifra superaba el $65 \% .{ }^{73}$ Aun cuando no se sabe con certeza cuántas armas circulan en el mercado ilegal, el número de decomisos habla por sí mismo: entre 2006 y 2012, la Secretaría de la Defensa Nacional (sEDENA) decomisó más de 140000 armas de fuego y casi 13 millones de municiones. ${ }^{74}$

71 "Armed Conflict Survey 2017", International Institute for Strategic Studies, 2017, cap. XIII.

72 Cifras de la Secretaría Ejecutiva del Sistema Nacional de Seguridad Pública.

73 C. Parsons y E. Weigend, "Beyond our Borders: How weak U.S. Gun Laws contribute to violent crime abroad”, Washington D.C., Center for American Progress, 2018, pp. 3-4.

74 SEDENA, "Informe de Rendición de Cuentas de la APF 2006-2012", SEDENA, 2012, p. 160. Durante el periodo que va de 1994 a 2000, la misma institución sólo había decomisado 41700 . Véase: M. Coss Nogueda, “Armas pequeñas y ligeras: Caso México”, México, Oxfam, 2005, p. 26. 
En segundo lugar, está el tema de la colusión entre autoridades estatales y criminalidad organizada y, más concretamente, el problema que supone que instituciones de seguridad hayan sido infiltradas por intereses criminales. El fenómeno no es nuevo; sin embargo, hay evidencia que apunta a que en los últimos 15 años el nivel de colusión entre crimen organizado y Estado se ha vuelto cada vez más profundo. ${ }^{75}$ La desaparición forzada de los 43 estudiantes de la Normal de Ayotzinapa en septiembre de 2014 develó la colusión entre agentes estatales con el crimen organizado, así como los mecanismos de impunidad que persisten. El caso es especialmente problemático: los policías municipales que participaron en el ataque de los estudiantes no solamente estaban cooptados, también poseían fusiles de fuego importados de forma legal de Alemania y Estados Unidos.

Un tercer fenómeno íntimamente ligado con el anterior es el uso de SALW en casos de violación a los derechos humanos por parte de autoridades estatales. El más emblemático, que implica a agentes estatales en violaciones a los derechos humanos, es el de la ejecución de 22 personas en Tlatlaya (Estado de México) -entre ellas dos menores de edad- en 2014. Otras masacres que involucran a agentes de seguridad incluyen eventos en Apatzingán (Michoacán) en enero de 2015 y en Tanhuato (Michoacán) en mayo del mismo año. La lista, sin embargo, es más larga y ya se ha sistematizado en informes de organizaciones no gubernamentales. ${ }^{76}$

Por último, está la probada incapacidad de las instituciones estatales por aplicar una política responsable de control de armas. Identificamos dos problemas centrales a este respecto: los resultados negativos que se desprenden de las auditorías realizadas al Registro Federal de Armas (responsabilidad de la SEDENA, única facultada para importar y distribuir armamen-

75 J. E. Garay-Salamanca y E. Salcedo-Albarán, Drug Trafficking, Corruption and States: How Illicit Networks Shaped Institutions in Colombia, Mexico and Guatemala, Bloomington, iUniverse, 2015.

${ }^{76}$ Por ejemplo, Open Society Justice Initiative, Atrocidades innegables: confrontando crimenes de lesa humanidad en México. 
to) y la proliferación de casos de armas reportadas como extraviadas o perdidas por las fuerzas de seguridad mexicanas. ${ }^{77}$ Mientras lo primero es resultado de la debilidad institucional que abarca todas la política de seguridad del Estado, lo segundo "demuestra un inadecuado manejo de los depósitos donde se resguardan [las armas] y deficiencias en su control y registro por parte de las corporaciones". ${ }^{78}$ En ambos casos, las variables principales son la corrupción e impunidad que permea en las instituciones en su conjunto. Así, sin un registro confiable de armas y con más de 17000 sALw reportadas como robadas de los depósitos policiacos y militares en el país entre 2006 y 2014, México difícilmente puede presentarse como un importador confiable de armas legales. ${ }^{79}$ Nuestra propia investigación sobre armas importadas por la SEDENA y armas distribuidas a policías esatales presenta igualmente graves incongruencias.

\section{La respuesta de Alemania y Estados Unidos a la crisis en México}

Para las empresas alemanas y estadounidenses, México no es un mercado menor. Históricamente, México ha dependido de tecnología proveniente de Estados Unidos y Alemania para la manufactura de sus propias SALw. ${ }^{80}$ La relevancia ac-

77 Para los problemas de registro de armas, véase: Coss Nogueda, “Armas pequeñas y ligeras: Caso México”, art. cit., p. 13. Sobre los casos de extravío y aparentes robos a policías y militares en México, véase P. Arriaga y M. Roldán Álvarez, "Armas de fuego en México: panorama en 2016”, en Raúl Benítez Manaut y Sergio Aguayo Quezada (eds.), Atlas de la seguridad y la defensa de México 2016, México, CASEde, 2017, pp. 157-167.

78 Ibid, p. 164.

${ }^{79}$ La estadística de las armas reportadas como robadas la obtenemos de [...], ibid., p. 165 .

${ }^{80}$ Así, por ejemplo, en 1979 México (por medio de la Fábrica de Armas de la SEDENA) adquirió patentes de producción por parte del gobierno alemán para la producción del fusil G3 y la pistola automática MP5 de la empresa Heckler \& Koch. Véase Bundesregierung, "Antwort der Bundesregierung auf die Kleine Anfrage der Abgeordneten Winfried Nacht- 
tual también está fuera de toda duda: en los últimos quince años, la SEDENA ha comprado SALW de tres empresas alemanas y de más de una docena de empresas estadounidenses. ${ }^{81}$ Sin embargo, ¿cómo se ha leído en cada país la crisis de derechos humanos en México a partir de su política de exportación de armas?

El más importante y controvertido caso de transferencias de SALW de Alemania a México es el cargamento de unos 10000 fusiles Heckler \& Koch G36 vendidos a la SEDENA entre 2006 y 2009 por un valor de más de 22 millones de euros. ${ }^{82}$

La condición impuesta por el BMwi a Heckler \& Koch para expedir el permiso era la no distribución de estas armas a cuatro estados de la República considerados especialmente conflictivos (Jalisco, Chihuahua, Chiapas y Guerrero). A pesar del veto, en 2011 varios reportes independientes mostraron que policías locales, e incluso actores no estatales de las regiones mencionadas, estaban en posesión de estas armas.

Aunque en México el tema no recibió demasiada atención, en Alemania tuvo consecuencias mediáticas, políticas e incluso judiciales. Al momento de escribir estas líneas, Heckler \& Koch enfrenta un proceso legal frente a las acusaciones de la fiscalía de Stuttgart por atentar contra la KWKG.

El caso Heckler \& Koch despertó el interés entre la sociedad civil por conocer e influir en la posición alemana respec-

wei, Dr. Wolfgang Strengmann-Kuhn, Marieluise Beck (Bremen), weiterer Abgeordneter und der Fraktion Bündnis 90/Die Grünen, Drucksache 16/12951", 8 de mayo de 2009.

${ }^{81}$ El dato sobre las empresas alemanas lo obtenemos de: Secretaría de la Defensa Nacional, "Respuesta a solicitud de información, número de folio 0000700176215”, 5 de diciembre de 2015. Refiere esencialmente a tres empresas: Heckler \& Koch, Carl Walther y Dynamit Nobel Defense. Los datos de las empresas estadounidenses los obtenemos de Secretaría de la Defensa Nacional, "Hoja de Respuesta a Solicitudes de Información 00007000075417”, 23 de mayo de 2017. Las principales empresas son Colt Defense, Sig Sauer, Dillon Aero y Glock.

${ }^{82}$ Sobre este caso: C. A. Pérez Ricart, "Armas alemanas en México: El caso de la exportación a México de los fusiles Heckler \& Koch G36”, México vía Berlín e. V., 2013. 
to a la crisis en México. Un primer logro fue la detención -probablemente definitiva- de un programa de cooperación y entrenamiento policial que iban a firmar ambos países en 2011. ${ }^{83}$ En el tema concreto de la exportación legal de armas, a finales de 2010 el gobierno alemán dejó de expedir permisos de exportaciones de SAlw a México. ${ }^{84}$ No es claro cuándo terminará el fin de la prohibición; sin embargo, en un documento de 2011 el gobierno señaló que esperaría al final de las investigaciones sobre el caso Heckler \& Koch para replantearse la posibilidad de continuar expidiendo permisos de exportaciones legales a México. ${ }^{85}$ Lo cierto es que desde entonces no se registran exportaciones de SALW de Alemania a México. Más todavía, tras la desaparición de los estudiantes en Ayotzinapa y la implicación de armas alemanas en el suceso, el BMwi ha hecho esfuerzos diplomáticos para que la sEDENA recupere el armamento otorgado a las policías locales. Hasta donde hemos podido saber, las policías locales de Guerrero han devuelto al menos 600 fusiles G36 al ejército mexicano. ${ }^{86}$ Asimismo, en Chihuahua se registró la devolución de 2100 G36 a la SEDENA. ${ }^{87}$ En otro acontecimiento, en febrero de 2015, el comisionado de Derechos Humanos de Alemania

${ }^{83} \mathrm{Al}$ respecto, véase: C. A. Pérez Ricart, "Die Zusammenarbeit in Sicherheitsfragen zwischen Mexiko und der Bundesrepublik Deutschland", Kriminologisches Journal 48, núm. 4, 2016, pp. 311-26.

${ }^{84}$ Brigitte Zypries, "Plenarprotokoll 18/123, Sitzung des Deutschen Bundestages", 23 de septiembre de 2015. Contamos con un documento que prueba que en 2016 la empresa alemana Dynamit Nobel Defense llegó a un acuerdo con la SEDENA para la venta de varios cientos de lanzallamas por un valor de 12600000 euros. La transacción, sin embargo, o bien no se concretó o no ha sido reconocida (hasta ahora) en ningún reporte oficial del gobierno alemán.

${ }^{85}$ Bundesregierung, "Antwort der Bundesregierung auf die Kleine Anfrage der Abgeordneten Andrej Hunko, Heike Hänsel, Wolfgang Gehrcke, weiterer Abgeordneter und der Fraktion DIE LINKE, Drucksache 17/8275", 28 de diciembre de 2011.

${ }^{86}$ Wolf-Dieter Vogel, "Polizei gibt Wummen ab", taz, 23 de abril de 2015.

${ }^{87}$ Juan Olivas y Luz Sosa, "Devolución de armas alemanas no afectará a la corporación: Seguridad Pública”, El Diario mx, 11 de mayo de 2015. 
(Menschenrechtsbeauftragte der Bundesregierung), Christoph Strässer, se disculpó públicamente con los padres de los desaparecidos de Iguala por el hecho de que los fusiles G36 hayan llegado a policías coludidos con el crimen. ${ }^{88}$

El gobierno de Estados Unidos ha tenido una reacción opuesta. A diferencia de Alemania, que ha impedido la exportación de SALw a México desde finales de 2010, la exportación proveniente del país vecino del norte ha crecido de manera exponencial en los últimos años. ${ }^{89}$ Así, por ejemplo, en 2015 se exportaron más de 20000 armas cortas y ligeras de Estados Unidos a México, incluyendo granadas..$^{90}$ Esto equivale más o menos a la mitad del total de las armas comercializadas por SEDENA aquel año. ${ }^{91} \mathrm{El}$ valor de las exportaciones de SALW, partes y municiones ha crecido de 1726000 dólares en 2002 hasta 39526000 en 2017, una cifra muy parecida a la media anual del periodo 2010-2017. De este modo, si durante el periodo 2002-2004 las empresas exportaron sALw, partes y municiones, por valor de poco más de 10 millones de dólares, entre 2015 y 2017 lo hicieron por valor de casi 123 millones. ${ }^{92}$ Como se explicó al principio de este texto, esta cifra corresponde solamente a acuerdos directos (DCS) y, por

${ }^{88}$ Peter Clausing, "Deutscher Beauftragter für Menschenrechte in Mexiko", Amerika 21 / Nachrichten und Analysen aus Lateinamerika, 28 de febrero de 2015, https://amerika21.de/2015/02/113205/straesser-mex

${ }^{89}$ American Friends Service Committee, "Where the Guns go: U.S: Arms and the Crisis of Violence in Mexico", 2016, p. 6. El incremento de ventas también se dio en el área de armas convencionales; esa área creció 10 veces en un periodo de 15 años. Para el periodo 2012-2015 alcanzó más de 3500 millones de dólares.

90 Utilizamos la base de datos del Norwegian Initiative on Small Arms Transfers, NISAT (base de datos), Researcher's Database, NISAT Database of Small Arms Transfers, http://nisat.prio.org/Trade-Database/ Researchers-Database/

${ }^{91}$ Secretaría de la Defensa Nacional, "Hoja de Respuesta a Solicitudes de Información 00007000075417”, p. 2.

${ }^{92}$ Utilizamos los datos del uscB. La página electrónica necesita clave de acceso. Véase: United States Census Bureau, uscb (sitio de internet). https://usatrade.census.gov/ 
lo tanto, no incluye las transferencias que involucra la Iniciativa Mérida. Como se señaló antes, tampoco contempla la cifra negra de armas que, vendidas en los cientos de armerías localizadas en el sur de Estados Unidos, se transportan ilegalmente a México. ${ }^{93}$

La coyuntura de Ayotzinapa no modificó la política de exportación de Estados Unidos hacia México. El que policías de Iguala también tuvieran fusiles de asalto de una empresa estadounidense (Colt, modelo AR-6530) no supuso un problema político ni provocó las disculpas de funcionarios estadounidenses. Contrario a lo sucedido con los Heckler \& Koch alemanes, los permisos de exportación de los fusiles Colt no incluían alguna cláusula que impidiera su distribución a policías de Guerrero u otras regiones. ${ }^{94}$ Para Estados Unidos tampoco parece ser relevante que $32 \%$ de los 52 monitoreos Blue Lantern realizados por el DDTC entre 2010 y 2017 tuvieran resultados "desfavorables". ${ }^{55}$

La exportación de armas estadounidenses hacia México no sólo ha crecido en los últimos años, también se prevé que alcance niveles sin precedentes. En marzo de 2015, el Departamento de Estado notificó al Congreso la aprobación de un acuerdo entre el gobierno mexicano y Sig Sauer, Inc. para la "fabricación de rifles y pistolas de Sig Sauer y la renovación de inventarios actuales", por un valor de hasta 266 millones de dólares. ${ }^{96}$ Se trata de un "Contrato de licencia de manufactura" que involucra la transferencia de tecnología para el

${ }^{93} \mathrm{Al}$ respecto la bibliografía es vasta. Un buen estudio sobre el tema es: Small Arms Survey, "Dribs and Drabs: The Mechanics of Small Arms Trafficking from the United States" (nota informativa), 2016.

${ }^{94}$ Assistant Secretary Legislative Affairs Julia Friefield a Senator Patrick Leahy, 18 de enero de 2017.

${ }^{95}$ Loc. cit.

${ }^{96}$ Sig Sauer Inc. es parte de una sociedad tenedora alemana, L\&O Holding. Su contraparte alemana, Sig Sauer GmbH, está acusada de exportar armas de forma ilegal vía Estados Unidos a países en conflicto. Véase: V. Kabisch, F. Obermaier y B. Obermayer, "Endstation Caracas", Süddeutsche Zeitung, 24 de julio de 2014. 
ensamblaje de armas cortas en México hasta 2024. ${ }^{97}$ Sig Sauer Inc. es la tercera productora y exportadora de pistolas más importante de Estados Unidos y un cliente habitual de la SEDENA, organismo que entre 2014 y 2016 compró más de 9000 pistolas de esa empresa que luego se distribuyeron a entidades del país donde existe evidencia de casos de colusión de policías con el crimen organizado, entre otras, Chihuahua, Veracruz, Tamaulipas y Morelos. ${ }^{98}$

\section{¿QUÉ EXPLICA LAS POSICIONES DIVERGENTES?}

La sección anterior mostró que Alemania y Estados Unidos asumieron posiciones por completo distintas en su política de exportación de armas a México. Mientras el país europeo dejó de otorgar permisos de exportación de salw, el Departamento de Estado continuó permitiendo la exportación de armas cortas y ligeras a México. La pregunta que queremos responder en esta sección es la de por qué dos países netamente exportadores deciden asumir posiciones diferenciadas frente a un mismo caso.

Reconocemos tres variables relevantes: 1) El tipo de sociedad civil que interviene en el tema: mientras en Alemania hay una gran influencia de organizaciones pro derechos humanos, en Estados Unidos esta perspectiva política ha quedado delegada a la participación de grupos conservadores; 2) los mayores o menores incentivos de los gobiernos en asumir los costos reflejados en la reputación de una política de exportación de armas sin considerar la situación de derechos humanos en el país receptor. Sostenemos que el lastre del pasado militarista ha llevado a los gobiernos alemanes de la

97 Secretaría de Marina, "Respuesta a solicitud de información, número de folio 0001300012417", 10 de marzo de 2017, p. 3.

98 Secretaría de la Defensa Nacional, "Hoja de Respuesta a Solicitudes de Información 0000700016317", 17 de febrero de 2017. Véase también: Secretaría de la Defensa Nacional, "Hoja de Respuesta a Solicitudes de Información 0000700000518”, 15 de febrero de 2018. 
posguerra a estar más dispuestos a incorporar ciertas nociones vinculantes de derechos humanos a su política de exportación de armas, algo casi inexistente en la posición estadounidense; 3) la capacidad de la industria exportadora de SALW de organizarse e influir en la toma de decisiones, muy fuerte en Estados Unidos y casi inexistente en Alemania.

La explicación sobre el prestigio internacional tiene preponderancia en la bibliografía especializada. ${ }^{99}$ Según ésta, aun cuando no tienen ningún incentivo material para hacerlo, algunos países exportadores están dispuestos a sacrificar una dimensión importante de su industria con tal de salvaguardar su reputación internacional en una época en la que el marco normativo de los derechos humanos cobra cada vez más relevancia en el concierto internacional. La aritmética es más bien simple: al asumir políticas restrictivas al comercio de SALW, los Estados exportadores ganan autoridad para impulsar otros temas de su política exterior potencialmente más relevantes. La premisa básica ha sido ya revisada por la escuela constructivista de las relaciones internacionales: los Estados no sólo persiguen intereses materiales, sino que buscan asociarse con ideas positivas que después rentabilizan internamente. Como puede entreverse, esta explicación subraya que la idea de políticas "más responsables" de exportación de armas no está aislada del surgimiento de normas que han conferido nuevos significados a términos como responsabilidad, seguridad o transparencia a escala internacional.

$\mathrm{Al}$ respecto, consideramos que el "escándalo" producido por el caso Heckler \& Koch en México fue suficientemente grande como para llevar al gobierno alemán a replantarse por entero su política de exportación de salw frente a este país. A finales de 2010, como ya revisamos, se dejaron de expedir permisos de exportación. La tesis es la siguiente: el costo de continuar exportando salw a México era mayor del que podía

${ }^{99}$ El mejor ejemplo es: J. L. Erickson, Dangerous Trade: Arms Exports, Human Rights, and International Reputation, Nueva York, Columbia University Press, 2015. 
permitirse un gobierno en búsqueda de "poder suave" a escala global. Lo anterior es cierto tanto para México como para otras zonas de conflicto. La tendencia a la baja de la exportación de salw a países no europeos es una prueba de ello.

En yuxtaposición, en Estados Unidos la reputación internacional ha sido interpretada en una clave distinta: no necesariamente desde la adopción de normas, sino desde la necesidad de mantener su poder militar en el globo. Donald Trump y su mensaje aislacionista de "Estados Unidos primero" representan a la perfección esta interpretación de "liderazgo" internacional.

A diferencia de Alemania, cuyos condicionantes históricos no le permiten interpretar su liderazgo internacional en esos términos, el gobierno de Estados Unidos es menos sensible a los costos que supone rechazar el multilateralismo en temas específicos. Nuestra hipótesis es que en esa clave también debe leerse su política de control de exportaciones de SALW.

A pesar de que con armas estadounidenses se han perpetrado igualmente crímenes de alto impacto en México, lo cierto es que no hay un "escándalo" comparado con el de las armas alemanas. Entre otras razones, porque el principal problema relativo a las armas entre México y Estados Unidos no es el comercio legal, sino el ilegal, y porque en ese país la sociedad civil activa en torno a este tema está dividida o se ha agrupado alrededor de una agenda en pro de las armas. ${ }^{100}$ Precisamente el interés específico de la sociedad civil en el tema es la segunda explicación del porqué Alemania y Estados Unidos tuvieron reacciones diferenciadas en su política de exportación de armas frente a México.

Si bien es cierto que en Estados Unidos ha crecido un movimiento social preocupado por el problema de la tenencia de armas dentro del país -con una proyección impresionante a partir de 2012-, éste apenas ha tenido contacto directo con la mucha más débil coalición de organizaciones preocupadas

${ }^{100}$ La mayor parte de las armas que circulan en México fueron importadas ilegalmente de Estados Unidos. 
por las armas fuera de Estados Unidos, particularmente en México. ${ }^{101}$ Así, en Estados Unidos el tema del control de exportación de armas ha sido relegado a especialistas y responsables de tomar decisiones; con pocas excepciones, no ha estado en el centro del debate público. ${ }^{102}$ Lo anterior no resta mérito al trabajo de algunos grupos. Por ejemplo, la Arms Control Association -agrupación que desde 1971 pugna por políticas de control de armas más efectivas-y el Forum on the Arms Trade -red de expertos y activistas que, además de dedicarse al trabajo de incidencia, dan continuidad al estudio de las implicaciones humanitarias, económicas y políticas de la transferencia de armas. Otras coaliciones, que a principios del siglo xxi fueron relevantes para la discusión -el US Small Arms Working Group y la International Action Network on Small Arms (IANSA) - ${ }^{103}$ perdieron su relevancia o se desintegraron en la última década. Es justo señalar, sin embargo, que muchos de los esfuerzos de la sociedad civil en Estados Unidos se han enfocado en oponerse a intervenciones militares directas, a denunciar el tráfico ilegal de armas y la firma de acuerdos de asistencia militar.

Las grandes organizaciones que continúan trabajando en forma activa en Estados Unidos son precisamente las que respaldan una política de flexibilización de la ley de exportaciones de armas. Así, por ejemplo, la National Rifle Association of America (NRA) ganó, en 1996, el estatus de organización no gubernamental ante Naciones Unidas. Desde entonces, y a la fecha, participa activamente en contra de cualquier regulación internacional al res-

${ }^{101}$ Lo cierto es que hay organizaciones avocadas a reducir esta distancia. Véase: C. Boggs y K. Rand, "Gun-Running Nation: How Foreign-Made Assault Weapons are Trafficked from the United States to Mexico and What to Do About It”, wola \& Violence Policy Center, 2015.

102 Erickson, "Saint or Sinner? Human Rights and U.S. Support for the Arms Trade Treaty", art. cit., p. 467.

103 Grillot, Stapley, y Hanna, "Assessing the Small Arms Movement: The Trials and Tribulations of a Transnational Network", art. cit. 
pecto. ${ }^{104}$ La administración de Trump podrá traer buenas noticias a esta agenda en los próximos años. ${ }^{105}$

Por último, no está de más señalar el peso e importancia que tiene la segunda enmienda de la Constitución de Estados Unidos en la discusión general sobre armas en ese país. La idea de un "derecho" inalienable a portar armas está en la base de la cultura política de gran parte de la sociedad. Una pregunta que no tocamos del todo en este artículo, pero que resulta inevitable, se refiere al efecto que esa petición de principio tiene sobre la discusión en torno a la exportación de armas. A modo de hipótesis sostenemos que no es menor y que se asume que ese "derecho" es igualmente transferible para ciudadanos de otros países. ${ }^{106}$

El caso de Alemania es muy distinto. Como ya se señaló, el rechazo al militarismo de la posguerra tuvo como una de sus consecuencias principales la temprana organización de un movimiento opositor a la industria armamentista. Con presencia local, regional y federal, una coalición de organizaciones de diferentes estratos de la sociedad civil ha logrado permear el debate público sobre el tema. Entre otras, sobresale la Gemeinsame Konferenz Kirche und Entwicklung (GKKE) -una asociación católica-evangélica que desde 1973 publica informes independientes sobre las exportaciones alemanas al resto del mundo-y la red Deutsches Aktionsnetz Kleinwaffen Stoppen (DAKs), coalición que agrupa a gran parte del movimiento pacifista alemán. Asimismo, centros de información como el Berliner Informationszentrum für Transatlantische Sicherheit (BITs) mantienen bajo revisión constante los reportes oficiales del Bundesregierung (go-

104 Sobre el trabajo de la NRA en Naciones Unidas y en otras campañas internacionales, véase D. Morton, "Gunning for the World", Foreign Policy 152, 2006, pp. 58-67.

105 M. Stone y M. Spetalnick, “Trump administration prepares to ease export rules for U.S. guns”, Reuters, 19 de septiembre de 2017, https:/ / www.reuters.com

106 Agradecemos a uno/una de los dictaminadores/dictaminadoras de este artículo por hacernos ver este punto. 
bierno federal). Por último, existen al menos una docena de campañas concurrentes que exigen el fin de la exportación de SALW alemanas a determinadas regiones del mundo. Todas han denunciado la exportación de SALw a México y forjado alianzas con organizaciones centradas en la protección de los derechos humanos en ese país -sobresale la Deutsche Menschenrechtskoordination Mexiko-, así como con periodistas y académicos independientes. En un contexto político en el que los partidos políticos refieren este tema en sus campañas electorales, el potencial que tienen estas organizaciones para influir es alto. Ayuda mucho la alianza informal que mantienen con algunos partidos políticos -SPD, los verdes (Bündnis 90/Die Grünen) y la izquierda (Die Linke)-, así como con parlamentarios que han referido al caso mexicano en diversas ocasiones a lo largo de la última década. ${ }^{107}$

La tercera variable para explicar las diferencias entre la posición alemana y la estadounidense se relaciona con la importancia relativa de la industria de SALW en el proceso político.

Si bien está fuera de toda duda la relevancia de la industria armamentista en las dos economías, la importancia relativa en Alemania de la industria de sALW es menor y se reduce a unas pocas empresas localizadas en contadas regiones. El número de empleos directos generados en la producción de SALW es apenas una pequeña fracción de los poco menos de 100000 que genera la totalidad de la industria armamentista en Alemania. ${ }^{108}$ Aunque las estadísticas no son concluyentes, su número posiblemente no supere el millar; esto, a pesar de que la cifra se infle de manera continua de-

107 Para algunos ejemplos, véase Pérez Ricart, "Die Zusammenarbeit in Sicherheitsfragen zwischen Mexiko und der Bundesrepublik Deutschland", art. cit.

108 Para una discusión sobre las tasa de empleo en la industria en Alemania, véase: M. Weber y T. Nielebock, "Deutsche Rüstungsexporte: eine Handreichung", Institut für Politikwissenschaft, Eberhard Karls Universität Tübingen, 2016, pp. 7-8. 
bido a intereses políticos. ${ }^{109}$ Más aún: la tendencia apunta a que el número real de empleos directos se reducirá debido al desplazamiento de la producción de empresas alemanas de SALW de su país de origen a Estados Unidos. ${ }^{110}$ Por lo demás, la representación de las empresas alemanas de SALw es marginal en la Bundesverband der Deutschen Sicherheits-und Verteidigungsindustrie (BDSV), el consorcio de agrupaciones que defiende los intereses de la industria armamentista en Alemania y cuyo poder político, aun con sus lazos con liberales y demócrata cristianos, continúa siendo limitado. ${ }^{111}$

En Estados Unidos, el poder relativo de la industria de SALW es mayor. Ésta presume crear poco menos de 150000 empleos directos y otros tantos indirectos. ${ }^{112}$ Las cifras del USCB son más conservadoras y, aunque reconocen la existencia de cientos de empresas en el sector, limitan a 17000 los empleos directos generados por la producción de sALw. ${ }^{113}$ Aun si hacemos caso a las cifras más altas, los empleos generados por la industria de SALW no supondrían más de $0.1 \%$ de los trabajos formales en Estados Unidos.

A pesar de lo anterior, la industria de sAlw ha sabido generar estrategias de lobbying que exceden su relevancia real en la creación de empleos. ${ }^{114}$ Sobresalen dos organizaciones: por un lado, la ya citada NRA y, por otro, una coalición de más de 8000 productores y comercializadores de armas cortas conocida como National Shooting Sports Foundation (NSSF). Ambas son muy conocidas por financiar cam-

${ }^{109}$ Sobre la sobreestimación de cifras, véase ibid, p. 11. Para una perspectiva histórica: K. Schomaker, P. Wilke y H. Wulf, Alternative Produktion statt Rüstung, Köln, Bund, 1987.

${ }^{110}$ Véase Pérez Ricart y Ramhorst, art. cit.

${ }^{111}$ Sobre el bDSv y sus lazos con la política alemana: Grässlin, Schwarzbuch Waffen Handel: Wie Deutschland am Krieg verdient, op. cit., pp. 183-200.

112 The Firearms Industry Trade Association, "Firearms and Ammunition Industry Economic Impact Report 2018”, 2018, p. 3.

${ }^{113}$ Datos del usci, https:/ / usatrade.census.gov/ (N. de la E. La página electrónica necesita clave de acceso).

114 "The outsize influence of the gun lobby", The Economist, 28 de noviembre de 2017, en https://www.economist.com 
pañas políticas y son precisamente las organizaciones que avanzan la agenda de rebajar los controles de exportación de SAlw. ${ }^{115}$ Más aún, como nos señalaron nuestros entrevistados, el proceso de expedición de permisos está viciado: en la práctica el DDTC está sujeto a fuertes presiones por parte de la industria para aceptar sin dilación todas las solicitudes de licencias comerciales. ${ }^{116}$

En conclusión: la sobrerrepresentación de la industria de SALW en la toma de decisiones no sólo ha impedido un cambio de paradigma en relación con la política de exportación de armas a México; también es una variable que impulsa hacia controles más laxos.

\section{Conclusiones}

En este artículo analizamos los sistemas de control de exportación de armas de Alemania y Estados Unidos, así como la forma en que cada país ha asumido, en su política de exportación, posiciones diferenciadas con respecto al caso mexicano.

Los resultados de la investigación dejan ver que, aun si durante los primeros ocho años del nuevo siglo varias empresas alemanas de armas habían comenzado una próspera relación de exportación con México, a finales de 2010 Alemania dejó de expedir permisos de exportación de sALw. Tal decisión -sumada a otras, como la cancelación de un acuerdo de cooperación policiaca- la explicamos por medio de tres variables: 1) los costos reputacionales de exportar SALW; 2) el tipo de sociedad civil que se moviliza a partir de este tema y 3) el peso de la industria armamentista.

115 L. Wheeler, "Planned shift on gun exports kicks up storm", The Hill, 11 de enero de 2018, http:/ / thehill.com

116 Así nos lo aseguraron funcionarios del DDTC en Washington D.C. en reunión sostenida en mayo de 2017. 
En contrapunto a la reacción alemana, el artículo no sólo mostró la tendencia al alta de la exportación de salw de Estados Unidos a México, sino que expuso como caso paradigmático la concreción de un nuevo convenio entre Sig Sauer y las Fuerzas Armadas de México. Esto, a pesar de los informes que revelan tortura, ejecuciones extrajudiciales, colusión entre autoridades y criminalidad organizada, así como casos alarmantes de extravío y robo de armas de fuego en México. El texto también demostró que, a pesar de que la bibliografía señala a Estados Unidos como el gold standard del control de exportación de armas, su sistema no contempla mecanismos que impidan que las SALw lleguen a regiones inestables o a manos de actores estatales con historiales cuestionables en materia de derechos humanos.

Este artículo se inscribe en el intento de resarcir la ausencia de investigación documental sobre la forma en que países exportadores de SALW enfrentan fenómenos de inestabilidad política o hechos de violación de los derechos humanos. Aun así, es largo el derrotero por recorrer para tener una mejor comprensión del fenómeno. En primer lugar, sería deseable la existencia de estudios que incluyan, también desde una perspectiva comparada, a otros países exportadores. En segundo lugar, es necesario un entendimiento más preciso de los mecanismos puntuales que llevan a que las instituciones encargadas de la expedición de permisos de exportación de SALW sean más o menos permeables a las presiones de todos quienes participan en el tema: desde organizaciones de la sociedad civil hasta la industria armamentista. En tercer lugar, los resultados de esta investigación invitan a un estudio más profundo de las estrategias de las organizaciones no gubernamentales para intervenir en el tema. En particular, consideramos importante ofrecer más espacio de denuncia a las víctimas. Así, por ejemplo, mientras que la exposición pública del dolor de las víctimas de minas antipersonales fue esencial para alcanzar una prohibición casi global de su uso, los testimonios de las víctimas de SALW apenas han recibido aten- 
ción. ${ }^{117}$ Un cambio en esa narrativa puede ayudar a subrayar la imperiosa necesidad de imponer controles cada vez estrictos a la exportación legal de sALw a escala global.

\section{REFERENCIAS BIBLIOGRÁFICAS}

Abramson, Jeff, "Trump Favors Arms Industry in Effort to Loosen Export Controls", Arms Control Association, Issue Briefs 10, núm. 6, 2018, pp. 1-6.

American Friends Service Committee, "Where the Guns go: U.S: Arms and the Crisis of Violence in Mexico", Estados Unidos, 2016.

Amnesty International, "Democratic Republic of Congo: Arming the East", AFR 62/006/2005, 2005.

“Armed Conflict Survey 2017", International Institute for Strategic Studies, 2017.

Arriaga, Paulina y Maura Roldán Álvarez, "Armas de fuego en México: panorama en 2016”, pp. 157-67, en Raúl Benítez Manaut y Sergio Aguayo Quezada (eds.), Atlas de la seguridad y la defensa de México 2016, Ciudad de México, CASEDe, 2017.

BogGS, Clay y Kristen Rand, "Gun-Running Nation: How ForeignMade Assault Weapons are Trafficked from the United States to Mexico and What to Do About It", wola \& Violence Policy Center, 2015.

Boutwell, Jeffrey y Michael Klare, "Small Arms and Light Weapons: Controlling the Real Instruments of War", Arms Control Today 28, núm. 6, 1998, pp. 15-23.

BrigitTe, Zypries, "Plenarprotokoll 18/123, Sitzung des Deutschen Bundestages", 23 de septiembre de 2015.

Bromley, Mark, Lawrence Dermody, Hugh Griffiths, Paul Holtom y Michael Jenks, "Transfers of Small Arms and Light Weapons to Fragile States: Strengthening Oversight and Control”, sIPRI, enero de 2013.

117 Véase: R. Price, "Reversing the Gun Sights: Transnational Civil Society Targets Land Mines", International Organization 52, núm. 3, 1998, pp. 613-644. 
Brzoska, Michael, "The Erosion of Restraint in West German Arms

Transfer Policy”, Journal of Peace Research 26, núm. 2, 1989, pp. 165-77.

Brzoska, Michael, Anton-Andreas Guha y Christian Wellmann,

Das Geschäft mit dem Tod: Fakten und Hintergründe der Rüstungsindustrie, Frankfurt, Eichborn Verlag, 1982.

Bundesregierung, "Antwort der Bundesregierung auf die Kleine Anfrage der Abgeordneten Andrej Hunko, Heike Hänsel, Wolfgang Gehrcke, weiterer Abgeordneter und der Fraktion die linke, Drucksache 17/8275”, 28 de diciembre de 2011.

, "Antwort der Bundesregierung auf die Kleine Anfrage der Abgeordneten Winfried Nachtwei, Dr. Wolfgang Strengmann-Kuhn, Marieluise Beck (Bremen), weiterer Abgeordneter und der Fraktion Bündnis 90/die Grünen, Drucksache 16/12951", 8 de mayo de 2009.

, "Bericht der Bundesregierung über ihre Exportpolitik für konventionelle Rüstungsgüter im Jahr 2016”, 2017.

, "Politische Grundsätze der Bundesregierung für den Export von Kriegswaffen und sonstigen Rüstungsgütern”, $B u$ lletin des Presse-und Informationsamtes der Bundesregierung 38 (1982), p. 309.

_ _ "Politische Grundsätze der Bundesregierung für den Export von Kriegswaffen und sonstigen Rüstungsgütern”, 2000.

Bureau of Alcohol, Tobacco, Firearms and Explosives, "Firearms

Commerce in the United States: Annual Statistical Update 2017”, 2017.

Center for Civilians in Conflict y Stimson Center, "With great Power:

Modifying US Arms Sales to Reduce Civilian Harm”, 2018.

Clausing, Peter, "Deutscher Beauftragter für Menschenrechte in

Mexiko", Amerika 21 / Nachrichten und Analysen aus Lateinameri$k a, 28$ de febrero de 2015, en https:/ /amerika21.de/2015/02/ 113205 /straesser-mex

Coss Nogueda, Magda, "Armas pequeñas y ligeras: Caso México”, México, Oxfam, 2005.

Directorate of Defense Trade Controls, Bureau of Political-Military Affairs, State Department, "End-Use Monitoring of Defense Articles and Defense Services Commercial Exports FY 2015", 
2016. http://pmddtc.state.gov/reports/documents/End_Use _FY2015.pdf

Erickson, Jennifer L., Dangerous Trade: Arms Exports, Human Rights, and International Reputation, Nueva York, Columbia University Press, 2015.

-, "Saint or Sinner? Human Rights and U.S. Support for the Arms Trade Treaty”, Political Science Quarterly 130, núm. , 2015, pp. $449-474$.

FranzblaU, Jeese y Cora Currier, "Mexican authorities implicated in violence, but U.S. security aid still flows", The Intercept, 8 de mayo de 2015, en https:// theintercept.com

Garay-Salamanca, Jorge Eduardo y Eduardo Salcedo-Albarán, Drug Trafficking, Corruption and States: How Illicit Networks Shaped Institutions in Colombia, Mexico and Guatemala, Bloomington, iUniverse, 2015.

GarcIa, Denise, Small Arms and Security: New Emerging International Norms, Londres, Routledge, 2006.

GRÄsslin, Jürgen, Schwarzbuch Waffen Handel: Wie Deutschland am Krieg verdient, Múnich, Heyne, 2013.

Grillot, Suzette, "Global Gun Control: Examining the Consequences of Competing International Norms", Global Governance 17, núm. 4, 2011, pp. 529-555.

Grillot, Suzette, Craig S. Stapley y Molly E. Hanna, “Assessing the Small Arms Movement: The Trials and Tribulations of a Transnational Network", Contemporary Security Policy 27, núm. 1, 2006, pp. 60-84.

Hartung, William D., "U.S. Conventional Arms Transfers: Promoting Stability or Fueling Conflict?”, Arms Control Today 25, núm. 9, noviembre de 1995, pp. 9-13.

Hillen, John, "Small Arms, Big Danger", The Baltimore Sun, 3 de julio de 2006.

Julia Friefield, Assistant Secretary Legislative Affairs, "Carta a Senator Patrick Leahy", 18 de enero de 2017.

Kabisch, Volkmar, Frederik Obermaier y Bastian Obermayer, "Endstation Caracas", Süddeutsche Zeitung, 24 de julio de 2014.

Kerr, Paul K., "Arms Sales: Congressional Review Process", Congressional Research Service, julio de 2017. 
McNerney, Michael, Jonah Blank, Becca Wasser, Jeremy Boback y Alexander Stephenson, "Improving Implementation of the Department of Defense Leahy Law". RAND Corporation, 2017. Morton, David, “Gunning for the World”, Foreign Policy 152, 2006, pp. 58-67.

Office of Defense Trade Controls, State Department, "Guidelines for preparing agreements", 2016, en: http://www.pmddtc.sta te.gov/licensing/agreement.html

Office of the Press Secretary, The White House, Presidential Policy Directive 27: United States Conventional Arms Transfer Policy, 2014.

, Presidential Policy Directive 34: United States Conventional Arms Transfer Policy, 1995.

Olivas, Juan y Luz Sosa, "Devolución de armas alemanas no afectará a la corporación: Seguridad Pública”, El Diario $m x, 11$ de mayo de 2015.

Open Society Justice Initiative, Atrocidades innegables: confrontando crímenes de lesa humanidad en México, Nueva York, Open Society Foundations, 2016.

Parsons, Chelsea y Eugenio Weigend, "Beyond our Borders: How weak U.S. Gun Laws contribute to violent crime abroad", Washington D.C., Center for American Progress, 2018.

Pérez Ricart, Carlos A., "Armas alemanas en México: El caso de la exportación a México de los fusiles Heckler \& Koch G36”, México vía Berlín e. V., 2013.

, "Die Zusammenarbeit in Sicherheitsfragen zwischen Mexiko und der Bundesrepublik Deutschland", Kriminologisches Journal 48, núm. 4, 2016, pp. 311-326.

Pérez Ricart, Carlos A. y Lotta Ramhorst, "De Alemania a Estados Unidos: el desplazamiento de la producción de armas cortas y ligeras. Nuevas prácticas, viejos negocios”, Agenda 12, México vía Berlín e. V., 2018.

Price, Richard, "Reversing the Gun Sights: Transnational Civil Society Targets Land Mines", International Organization 52, núm. 3, 1998, pp. 613-644.

Schomaker, Klaus, Peter Wilke y Herbert Wulf, Alternative Produktion statt Rüstung, Köln, Bund, 1987. 
Secretaría de la Defensa Nacional, sedena, "Hoja de Respuesta a Solicitudes de Información 0000700000518”, México, 15 de febrero de 2018.

—, "Hoja de Respuesta a Solicitudes de Información 0000700016317 ”, México, 17 de febrero de 2017.

, "Hoja de Respuesta a Solicitudes de Información 0000 7000075417”, México, 23 de mayo de 2017.

, "Informe de Rendición de Cuentas de la APF 20062012”, México, Secretaría de la Defensa Nacional, 2012.

, "Respuesta a solicitud de información, número de folio 0000700176215 ", México, 5 de diciembre de 2015.

Secretaría de Marina, "Respuesta a solicitud de información, número de folio 0001300012417”, México, 10 de marzo de 2017.

Small Arms Survey, "Documenting Small Arms and Light Weapons" (nota informativa), Ginebra, Small Arms Survey, 2015.

_ king from the United States" (nota informativa), 2016.

, "Producers of Small Arms, Light Weapons, and their Ammunition", Research Notes Weapons and Markets, 43, 2014.

, Small Arms Survey 2012: Moving Targets, Cambridge, Cambridge University Press, 2012.

, Small Arms Survey 2015: Weapons and the World, Cambridge, Cambridge University Press, 2015.

Special Inspector General for Iraq y Reconstruction, "Iraqi Security Forces: Weapons Provided by The U.S. Department of Defense Using the Iraq Relief and Reconstruction Fund", Virginia, 2006.

STOHL, Rachel, "United States weakens outcome of un Small Arms and Light Weapons", Arms Control Association, 1 de septiembre de 2001, en: https://www.armscontrol.org/act/2001_09/ stohlsept01

Stone, David R., "Imperialism and Sovereignty: The League of Nations' Drive to Control the Global Arms Trade", Journal of Contemporary History 35, núm. 2, 2000, pp. 213-230.

Stone, Mike y Matt Spetalnick, "Trump administration prepares to ease export rules for U.S. guns", Reuters, 19 de septiembre de 2017, en: www.reuters.com 
The Firearms Industry Trade Association, "Firearms and Ammunition Industry Economic Impact Report 2018”, 2018.

"The outsize influence of the gun lobby", The Economist, 28 de noviembre de 2017, en: www.economist.com

Theohary, Catherine A., "Conventional Arms Transfers to Developing Nations, 2007-2014”, Congressional Research Service, 2015.

Thrall, Trevor y Caroline Dorminey, "Risky Business: The Role of Arms Sales in U.S. Foreign Policy", Policy Analysis, Cato Institute, marzo de 2018.

Tracey, Michael, "Trump aiming to toss ailing gunmakers a lifeline worth millions", The Young Turks, 30 de abril de 2018, en https://tytnetwork.com

Trump, Donald J., "National Security Presidential Memorandum Regarding U.S. Conventional Arms Transfer Policy", 19 de abril de 2018.

United Nations Office on Drugs and Crime, unOdc, Study on Firearms 2015, Viena, UNODC, 2015.

United Nations Register of Conventional Arms, UnRocA, Transparency in the global reported arms trade (sitio de internet), en https://www.unroca.org/

Vogel, Wolf-Dieter, "Polizei gibt Wummen ab", taz, 23 de abril de 2015.

WAltz, Susan, "US Policy on Small Arms Transfers: A Human Rights Perspective", Human Righs \& Human Welfare Working Paper, 43, 2007.

Weber, Max y Thomas Nielebock, "Deutsche Rüstungsexporte: eine Handreichung”, Institut für Politikwissenschaft, Eberhard Karls Universität Tübingen, 2016.

Wezeman, Pieter D. y Siemon T. Wezeman, "The 2015 UN Register on Conventional Arms: Still Time to Improve", SIPRI, 18 de septiembre de 2015.

Wheeler, Lydia, "Planned shift on gun exports kicks up storm", The Hill, 11 de enero de 2018, en http://thehill.com 


\section{INSTRUMENTOS JURÍDICOS, INFORMES Y REPORTES}

Convención de las Naciones Unidas contra la Delincuencia Organizada Transnacional, 2000.

Instrumento internacional que permita a los Estados identificar y rastrear, de forma oportuna y fidedigna, las armas pequeñas y ligeras ilícitas (APAL), 2005.

Posición común 2008/944/PESC del Consejo por la que se definen las normas comunes que rigen el control de las exportaciones de tecnología y equipos militares", Diario Oficial de la Unión Europea, 8 de diciembre de 2008.

Protocolo contra la Fabricación y el Tráfico Ilícitos de Armas de Fuego, sus Piezas y Componentes y Municiones, 2001.

The Wassenaar Arrangement on Export Controls for Conventional Arms and Dual-Use Goods and Technologies, 1996.

Tratado sobre el Comercio de Armas (TCA), 2014. 
